OPEN ACCESS

Edited by:

Benoit Schoefs,

Le Mans Université, France

Reviewed by:

Kosuke Fukui,

Okayama University of Science,

Japan

Tibor Janda

Centre for Agricultural Research

(MTA), Hungary

Libo Xing,

Northwest A\&F University, China

*Correspondence:

Jessica Bertheloot

jessica.bertheloot@inra.fr

Specialty section:

This article was submitted to

Plant Physiology,

a section of the journal

Frontiers in Plant Science

Received: 13 June 2019

Accepted: 18 September 2019

Published: 18 October 2019

Citation:

Schneider A, Godin C, Boudon F, Demotes-Mainard S, Sakr $S$ and Bertheloot J (2019) Light Regulation of Axillary Bud Outgrowth Along Plant

Axes: An Overview of the Roles of

Sugars and Hormones.

Front. Plant Sci. 10:1296.

doi: 10.3389/fp/s.2019.01296

\section{Light Regulation of Axillary Bud Outgrowth Along Plant Axes: An Overview of the Roles of Sugars and Hormones}

\author{
Anne Schneider ${ }^{1}$, Christophe Godin'2, Frédéric Boudon ${ }^{3}$, Sabine Demotes-Mainard", \\ Soulaiman Sakr ${ }^{1}$ and Jessica Bertheloot ${ }^{1 *}$
}

${ }^{1}$ IRHS, INRA, Agrocampus-Ouest, Université d'Angers, SFR 4207 QuaSaV, Beaucouzé, France, ${ }^{2}$ Laboratoire Reproduction et Développement des Plantes, Univ Lyon, ENS de Lyon, UCB Lyon 1, CNRS, INRA, INRIA, Lyon, France, ${ }^{3}$ CIRAD, UMR AGAP \& Univ. Montpellier, Montpellier, France

Apical dominance, the process by which the growing apical zone of the shoot inhibits bud outgrowth, involves an intricate network of several signals in the shoot. Auxin originating from plant apical region inhibits bud outgrowth indirectly. This inhibition is in particular mediated by cytokinins and strigolactones, which move from the stem to the bud and that respectively stimulate and repress bud outgrowth. The action of this hormonal network is itself modulated by sugar levels as competition for sugars, caused by the growing apical sugar sink, may deprive buds from sugars and prevents bud outgrowth partly by their signaling role. In this review, we analyze recent findings on the interaction between light, in terms of quantity and quality, and apical dominance regulation. Depending on growth conditions, light may trigger different pathways of the apical dominance regulatory network. Studies pinpoint to the key role of shoot-located cytokinin synthesis for light intensity and abscisic acid synthesis in the bud for R:FR in the regulation of bud outgrowth by light. Our analysis provides three major research lines to get a more comprehensive understanding of light effects on bud outgrowth. This would undoubtedly benefit from the use of computer modeling associated with experimental observations to deal with a regulatory system that involves several interacting signals, feedbacks, and quantitative effects.

Keywords: light, hormones, sugar, bud outgrowth, branching, apical dominance, cytokinins, R:FR

\section{INTRODUCTION}

As sessile organisms, plants have to adapt to their growth environment. One important way is to adapt their branching architecture, above and below grounds, to accommodate endogenous (e.g., water and carbon status) and exogenous (light, space) constraints. In this process, branching regulation plays a crucial role as it defines strategies whereby plants colonize the underground and aerial spaces. Different environmental factors have been shown to impact this process, such as mineral or water supply to the roots, light, or temperature (Bouguyon et al., 2012; de Jong et al., 2014; Pierik and Testerink, 2014; Li-Marchetti et al., 2015). In the past two decades, due to spectacular advances in biotechnology, imaging, molecular biology, and computational modeling, major breakthroughs have been made in the understanding of the physiological regulation of branching of aerial axes. 
In particular, the veil on the key mechanisms whereby light regulates aerial branching on plant axes has been partly lifted.

During growth, apical meristems of plant axes produce sequences of phytomers. One phytomer is composed of an internode with its axillary leaf and one or several axillary buds. Once initiated, axillary buds themselves may in turn enter growth immediately (sylleptic buds), or they can remain latent (proleptic buds) until some external event to the buds triggers their outgrowth (Lang et al., 1987; Kieffer et al., 1998; Barthelemy and Caraglio, 2007). This latter two-phase strategy is very frequent in both annual or perennial plants and has been shown to result from the dominance of the growing apex over its axillary meristems. This phenomenon, called apical dominance, offers plants the possibility to develop in a parsimonious way while preserving the possibility of branching to adapt their development to changing physiological or environmental contexts (Cline, 1994).

Light in particular has been recognized as a major modulator of the expression of apical dominance for decades. For example, increasing light intensity in photosynthetically active radiation (PAR) often results in an increase of the total number of lateral branches that develop on a given axis, thus reducing apical dominance (Mitchell, 1953; Su et al., 2011; Demotes-Mainard et al., 2013; Leduc et al., 2014). Likewise, a change in light quality, such as a high red-to-far-red wavelength ratio (R:FR) due to the use of red LEDs in a greenhouse or to gaps in a canopy, often leads to an increase of the number of outgrowing branches (DemotesMainard et al., 2016). In principle, these modulations may result from either an increase of the total number of primary nodes or from the probability for a bud to grow out. Light may affect both processes, resulting in significant modulations of branching intensity and plant architecture. Finally, light may also, in a more subtle way, affect the time taken by axillary buds to enter into growth (Bos and Neuteboom, 1998; Gautier et al., 1999; Evers et al., 2006; Demotes-Mainard et al., 2016).

The nature of the physiological or biophysical mechanisms whereby light interacts with the process of apical dominance and participates to releasing axillary bud latency is still largely elusive. A better understanding of these mechanisms requires identifying how light interacts with the physiological mechanisms regulating apical dominance. Two major putative mechanisms of apical dominance have been debated in the literature over the last decades. First, it has been experimentally shown on a variety of plant species that apical dominance is mediated by the plant hormone auxin, produced at the growing apex, and transported downward through the vascular tissues of the stem (Thimann and Skoog, 1933; Cline, 1996; Ongaro and Leyser, 2008). In this view, the leading apex continuously produces auxin, which reaches bud neighborhood through basipetal transport, and controls bud outgrowth indirectly. Two main signaling cascades have been identified (Domagalska and Leyser, 2011): (i) auxin in the stem controls the production of two other hormones, cytokinins and strigolactones, that move into the bud to control its outgrowth (second messenger theory); and (ii) auxin transport itself prevents auxin export out of the bud, a process necessary for bud outgrowth (canalization theory). These signaling cascades inhibit bud outgrowth as long as the main apex keeps producing auxin. This signaling hypothesis has long been challenged by a second hypothesis based on competition for resources (Luquet et al., 2006).
This alternative view is based on the idea that during growth, plant organs compete for nutrients, and growing organs divert the nutrient resources from the freshly created buds. Deprived of resources, these buds remain latent as long as the main apex continues to grow. It was recently suggested that both hypotheses could be coupled in the regulation of bud outgrowth (Barbier et al., 2015; Barbier et al., 2019; Bertheloot et al., 2019).

In this review, we analyze how the effect of light on bud outgrowth has been interpreted in the context of the two main paradigms thought to be at the origin of apical dominance (which excludes the question of endodormancy in perennial plants). While previous review mainly focused on light effects in the vicinity of the bud (Leduc et al., 2014), this review aims to analyze how current knowledge from physiological and modeling studies helps to get a comprehensive understanding of light effects at the plant level. We start by a brief description of the main endogenous regulators of apical dominance, and their interaction and modulation at the plant scale. The hormonal regulation is described in a first section, while the regulation by the competition for nutrients is described in a second section. Then, we analyze the current knowledge about how light interacts with the previously identified endogenous network, including hormones and nutrients. We finally discuss the major gaps in the building of a comprehensive understanding of light-mediated bud outgrowth regulation and stress the potential complexity of the regulatory network, involving interactions between several regulators, dose-dependent effects, and feedback processes. We discuss why further detailed and quantitative analysis of this interaction will most probably require combining experimental and computational modeling approaches.

\section{HORMONAL REGULATION OF BUD OUTGROWTH}

\section{Regulation of Apical Dominance in the Shoot The Regulators of Apical Dominance: Auxin, Cytokinins, and Strigolactones}

Auxin, a plant hormone produced in the apical region and transported downwards through the stem, has long been considered as the orchestrator of apical dominance in plants (Thimann and Skoog, 1933; Thimann and Skoog, 1934; Rinne et al., 1993; Ljung et al., 2001; Ongaro and Leyser, 2008; Teichmann and Muhr, 2015). While decapitation of the growing shoot tip promotes bud outgrowth, exogenous auxin applied to the decapitated shoot tip usually restores bud outgrowth inhibition (Thimann and Skoog, 1933; Thimann and Skoog, 1934; Cline, 1996). Furthermore, plants with reduced or increased auxin signaling/level display increased or reduced branching levels, respectively (Romano et al., 1991; Booker et al., 2003).

Auxin acts in an interconnected way with two other hormones, cytokinins (CKs) and strigolactones (SLs). CKs act as shoot-branching inducers that have an antagonistic effect to auxin on bud outgrowth (Wickson and Thimann, 1958; Sachs and Thimann, 1967; Shimizu-Sato et al., 2009; Mueller and Leyser, 2011). SLs act as shoot-branching repressors and enhance the inhibiting effect of auxin on branching (Beveridge, 
2000; Beveridge, 2006 for reviews; Gomez-Roldan et al., 2008; Umehara et al., 2008; Crawford et al., 2010). While CKs and SLs are synthesized in both shoots and roots, only CKs can move through both the xylem sap (tZ-type) and the phloem sap (iP-type) (Bangerth, 1994; Mader et al., 2003; Kudo et al., 2010; Mueller and Leyser, 2011). SLs move primarily acropetally through the transpiration stream of the xylem sap, while their receptor-protein D14-is transported through the phloem to axillary buds in rice (Kohlen et al., 2011; Kameoka et al., 2016).

Auxin cannot enter buds (Prasad et al., 1993; Booker et al., 2003) and indirectly inhibits bud outgrowth. Several years of experiments have demonstrated that auxin acts through at least two non-exclusive mechanisms at the nodal segment and shoot scales, respectively (see Domagalska and Leyser, 2011; Rameau et al., 2015).

\section{The Regulating System At the Scale of the Nodal Segment Adjacent to the Bud}

In a theory known as "the second messenger theory," auxin in the nodal segment adjacent to the bud down-regulates CKs and up-regulates SLs, which are both supposed to migrate into the adjacent bud to control its outgrowth. The direct action of CKs and SLs in buds is supported by exogenous application of CKs and SLs on buds, which stimulated and inhibited their outgrowth, respectively (Sachs and Thimann, 1967; Gomez-Roldan et al., 2008; Dun et al., 2012). Furthermore, CK biosynthesis was rapidly enhanced in the nodal stem segment, and the CK content increased in the bud in response to auxin depletion, and these behaviors were prevented by exogenous auxin supply (Nordstrom et al., 2004; Tanaka et al., 2006; Liu et al., 2011; Li et al., 2018). By contrast, auxin depletion resulted in a rapid repression of SL biosynthesisrelated genes in the stem, a behavior prevented by exogenous auxin application (Foo et al., 2005; Zou et al., 2006; Hayward et al., 2009).

The integration of the two antagonistic regulators CKs and SLs is at least partly mediated by the TCP transcriptional regulator TEOSINTE1/BRANCHED1 (TB1/BRC1) in the bud (for reviews Rameau et al., 2015; Wang et al., 2019). BRC1 locally inhibits bud outgrowth, and its transcript level can be downregulated by CKs and upregulated by SLs. However, the expression level of OsTB1/FC1 (Oryza sativum Teosinte1/Fine Culm1) in rice was insensitive to SLs (Minakuchi et al., 2010; Guan et al., 2012), and CKs promoted bud activation in pea $b r c 1$ mutants (Braun et al., 2012). These results indicate that integration of CKs and SLs also involves a BRC1-independent pathway.

\section{The Systemic Regulation System}

In the "auxin canalization" theory, auxin transport in the stem is a systemic signal that prevents auxin export out of buds independently of any messengers relaying auxin signaling from the stem to the bud, and auxin export out of buds is necessary for their outgrowth. This theory relies on the observed tight correlation between bud outgrowth and auxin export out of the bud (Li and Bangerth, 1999; Bennett et al., 2006; Balla et al., 2011). As initially proposed by Sachs (1981) in the context of vascular strand differentiation, lateral auxin flow from the buds to the stem could be inhibited by the process of auxin canalization in the main stem, whereby the auxin flux upregulates and polarizes its own transport in one direction. From the 2000s, the identification of PIN auxin efflux carriers and visualization techniques based on PIN immunolocalization demonstrated the existence of a positive feedback between the auxin flow and its own transport. PIN polar targeting at the level of cell plasma membranes directs auxin flow, and this process is positively feedback-regulated by auxin itself (Sauer et al., 2006; Wisniewska et al., 2006). Introduction of such a feedback in a computer model confirmed the plausibility of the canalization theory. Prusinkiewicz et al. (2009) demonstrated through simulations that this feedback led to high auxin fluxes in the main stem, which may in turn prevent any lateral auxin flux from axillary buds. By stating that buds cannot enter sustained growth if they do not export their own auxin, auxin canalization in the main stem may thus explain bud inhibition during apical dominance. In this process, the directionality of canalization is determined by the auxin source that becomes active first (the apical one during apical dominance). Such a model also simulated several branching phenotypes observed in Arabidopsis mutants for auxin homeostasis or transport.

The discovery that SLs dampen polar auxin transport in the stem by down-regulating PIN accumulation in xylem parenchyma cells and triggering the rapid removal of PIN from the plasma membrane further confirmed the plausibility of the canalization theory (Bennett et al., 2006; Crawford et al., 2010; Xu et al., 2015; Li et al., 2018). A computational model in which the action of SLs is represented as an increase in the rate of removal of the auxin export protein-PIN-from the plasma membrane reproduced auxin transport and shoot branching phenotypes observed in various mutant combinations and SL treatments, including the counterintuitive ability of SLs to promote or inhibit shoot branching depending on the auxin transport status of the plant (Shinohara et al., 2013). Furthermore, exogenous supply of low doses of auxin transport inhibitors to the stem of SL mutants of Arabidopsis led to a phenotype close to that of wild-type plants, in accordance with a main role of auxin transport in determining the number of buds that grow out into branches (Bennett et al., 2006; Lazar and Goodman, 2006; Lin et al., 2009). However, even if several biological and modeling pieces of evidence support the canalization theory, the nature of the mechanism inducing export of axillary bud auxin into the stem is still relatively abstract (Prusinkiewicz et al., 2009).

\section{Dynamic Regulation of Bud Outgrowth Along a Same Axis}

The release of apical dominance leads to bud outgrowth at given positions on the plant depending on the plant species. Outgrowth of these buds then inhibits outgrowth of the other buds on the axis (Morris, 1977). In garden pea, the inhibition exerted by a growing bud on the buds below was related to auxin synthesized and exported by the growing bud and transported downward in the main stem (Balla et al., 2016). This mechanism limits excessive branching that may be detrimental for the plant.

SLs also appear as main components of this phenomenon and could act through a double feedback process (Dun et al., 2009b). In a first feedback, branching initiation increases SL biosynthesis through a branch-derived signal, probably auxin, 
which could contribute to further inhibit bud outgrowth. This regulation scheme was identified from the experimental observation that the initiation of a new branch in garden pea correlated locally with the up-regulation of SL biosynthesis genes in the corresponding node, and this upregulation was prevented by branch removal (Dun et al., 2009b). Second, SL deficiency in the node, which contributes to promote bud outgrowth, activates a feedback signal that up-regulates SL biosynthesis and decreases CKs in the xylem sap, thus contributing to prevent bud outgrowth. At the origin of this hypothesis, SL mutants of different species (except pea rms2) were observed displaying reduced CKs in the xylem sap and higher expression of SL biosynthesis genes, while exogenous SL supply repressed SL biosynthesis (Foo et al., 2005; Snowden et al., 2005; Foo et al., 2007; Drummond et al., 2009; Hayward et al., 2009). Computer simulations support this double SL-based regulating system in pea branching regulation as they capture the overall experimental phenotypes of branching, SL biosynthesis gene expression, and xylem-sap CKs that are observed for different graft combinations between mutant and wild-type pea (Dun et al., 2009b).

In garden pea, the feedback signal derived from SL perception is dependent on RMS2 and moves from shoots to roots (Beveridge, 2000; Foo et al., 2005; Foo et al., 2007). The chemical nature of the RMS2-dependent feedback has been extensively discussed (Ongaro and Leyser, 2008; Dun et al., 2009a). Ligerot et al. (2017) recently demonstrated that protein RMS2 functions as an auxin receptor. They also observed that SL root-feeding, as a disruption of auxin transport, repressed auxin biosynthesis in the shoot. This suggests the existence of a feedback loop in which auxin depletion in the stem stimulates SL biosynthesis in an RMS2-dependent manner in the roots, which in turn stimulates auxin biosynthesis in the shoot.

\section{Contribution of Roots to Bud Outgrowth}

As mentioned above, CK and SL biosynthesis in the shoot are main components of auxin-mediated apical dominance. But CKs and SLs are also synthesized in roots and root-derived CKs and SLs are transported in the shoots through the xylem and also contribute to stimulate and inhibit shoot branching, respectively (Beveridge, 2000; Young et al., 2014; Muller et al., 2015).

Root-derived CKs were long believed to contribute to the bud outgrowth response to decapitation because the xylemsap CK content increases after decapitation and accumulates in buds, and this is prevented by exogenous auxin supply (Bangerth, 1994; Turnbull et al., 1997; Mader et al., 2003). However, the absence of a rapid response of CK-related biosynthesis genes in roots indicates that root-derived CKs may have a secondary role in this process (Tanaka et al., 2006). Recent experiments comparing root-bearing plants and root-depleted isolated nodal stem segments indicate that root-derived CKs may in fact antagonize the effect of auxin in apical dominance. Decapitated plants of garden pea SL mutants were indeed unresponsive to auxin supply, due to the antagonistic effect of root-derived CKs on the inhibitory effect of auxin, while the isolated nodal stem segments (without root-derived CKs) were auxin responsive (Young et al., 2014). In Arabidopsis, intact auxin-producing CK-synthesis/signaling mutants were accordingly less branched than wild-type plants, while the isolated nodal segment bud response to auxin was not impaired in CK mutants as compared to the wild-type (Muller et al., 2015). Since CK biosynthesis in the roots is promoted by high nitrogen nutrition (Takei et al., 2002; Xu et al., 2015), root-derived CKs could antagonize auxin-mediated apical dominance in case of a high soil nitrogen content by modulating the shoot CK levels. In line with this, CK mutants of Arabidopsis exhibited an altered positive branching response to an increase in the soil nitrogen conditions (Muller et al., 2015). On the opposite, root-derived SLs, sensitive to phosphate or nitrogen deficiency or water stress (Ha et al., 2014; Cochetel et al., 2018; Mostofa et al., 2018), could strengthen auxin-mediated apical dominance in case of a low soil nutrient status or water stress. Accordingly, root-derived SLs have been reported to mediate the effect of soil phosphate deficiency on shoot branching (Kohlen et al., 2011; Xi et al., 2015).

\section{Regulation of Bud Outgrowth by Other Hormones}

Abscisic acid (ABA) is well known for its role in plant adaptation to abiotic stresses (Vishwakarma et al., 2017), and gibberellins (GAs) modulate a range of processes such as cell elongation and fruit maturation (see Olszewski et al., 2002; Yamaguchi, 2008; Hartmann et al., 2011; Ragni et al., 2011). They both take part to bud outgrowth regulation, but their role has been less investigated than the roles of auxin, CKs, and SLs.

The effect of GAs on bud outgrowth varies strongly among species. GAs inhibit shoot branching in rice (Lo et al., 2008; Ito et al., 2018), bahiagrass (Agharkar et al., 2007), Arabidopsis (Silverstone et al., 1997), hybrid aspen (Mauriat et al., 2011), and tomato (Martinez-Bello et al., 2015). The exact mechanism behind their effect remains elusive and might be linked to the modification of SL biosynthesis (Ito et al., 2017) and an increase of sugar sink strength (see below) (Buskila et al., 2016). In perennial woody plants such as rose and Jatropha curcas, GAs are promoters of bud outgrowth (Choubane et al., 2012; Ni et al., 2017). In apple, exogenous application of GAs to axillary buds did not promote outgrowth (Tan et al., 2018).

The role of $\mathrm{ABA}$ as an inhibitor of bud outgrowth was long hypothesized based on the observations that exogenous ABA supply inhibits bud outgrowth (White and Mansfield, 1977; Chatfield et al., 2000; Cline and Oh, 2006; Corot et al., 2017; Yuan et al., 2018) and that the bud ABA content is negatively correlated to the bud ability to grow out. In particular, the bud ABA level decreases in response to decapitation and increases in response to exogenous auxin supply in annual plants (Eliasson, 1975; Everatbourbouloux and Charnay, 1982; Knox and Wareing, 1984; Gocal et al., 1991), and ABA accumulates during cold-induced bud dormancy in perennial plants (Rohde et al., 1999; Arora et al., 2003; Wang et al., 2016a). Mutants recently confirmed a role of ABA in bud outgrowth regulation. Arabidopsis mutants deficient in ABA biosynthesis (nced3-2 and aba2-1) displayed higher bud outgrowth frequency (Reddy et al., 2013; Yao and 
Finlayson, 2015). Similarly, genetically altered poplar with reduced sensitivity to $\mathrm{ABA}$ exhibited enhanced shoot branching (Arend et al., 2009).

ABA has been reported to act downstream of auxin signaling (AUXIN-RESISTANT 1 AXR1), MORE AXILLARY BRANCHED (MAX) signaling (MAX2), and BRANCHED1 (BRC1) gene (Gonzalez-Grandio et al., 2013; Yao and Finlayson, 2015; Gonzalez-Grandio et al., 2017). AtBRC1 directly induces ABA synthesis in the bud by upregulating the expression of 9-CIS-EPOXICAROTENOID DIOXIGENASE 3 (NCED3), which encodes a key ABA-synthesis enzyme (Yao and Finlayson, 2015; Gonzalez-Grandio et al., 2017). ABA may partly inhibit bud outgrowth by reducing auxin biosynthesis and transport within the bud and also cell multiplication (Yao and Finlayson, 2015), which may impair bud capacity to export its own auxin and to grow out (Prusinkiewicz et al., 2009). ABA is also synthesized outside the bud and can access the buds (Everatbourbouloux, 1982; Lacombe and Achard, 2016). This raises the question of the role of such externally synthesized ABA in the control of bud outgrowth. ABA exogenously supplied to the stem below the bud inhibited bud outgrowth but did not do so when supplied above the bud, indicating a likely preferential role of upstream xylemtransported ABA (Cline and Oh, 2006). In barley, ABA was reported to suppress SL biosynthesis in the basal part of the plant and roots, which in this case promoted tiller emergence (Wang et al., 2018). These findings indicate the complexity of ABA-dependent bud outgrowth regulation and its interactions with other branching-related hormonal networks.

\section{Summary}

So far, many studies have focused on understanding how auxin, synthesized by growing apical organs and transported downwards through the stem in annual plants, acts to inhibit the outgrowth of a bud without entering the bud during apical dominance. They highlighted an intricate regulatory network described in Figure 1 that displays two pathways. In the first pathway, auxin acts through a canalization mechanism that creates a main flux of auxin downwards and inhibits the initiation of auxin fluxes from lateral buds. In the second pathway, auxin acts more locally through its concentration in the node which modulates CK and SL biosynthesis, which in turn relay the auxin signal from the stem to the bud. CK and SL signals are integrated in the bud through BRC1-dependent and -independent pathways. BRC1 acts at least partly by up-regulating ABA biosynthesis.

The relationship between both pathways is not fully understood. Both pathways probably interact because SLs also control auxin transport, and CKs were recently reported to control auxin efflux carrier proteins (PIN3, PIN4, PIN7) in Arabidopsis (Waldie and Leyser, 2018). From a temporal point of view, auxin transport regulation could come after local regulation, as indicated experimentally for garden pea (Chabikwa et al., 2019). Intriguingly, the role of CKs as a second messenger has recently been questioned for Arabidopsis because isolated nodal segments of mutants deficient in CK biosynthesis or signaling exhibited a normal response to exogenous auxin (Muller et al., 2015).

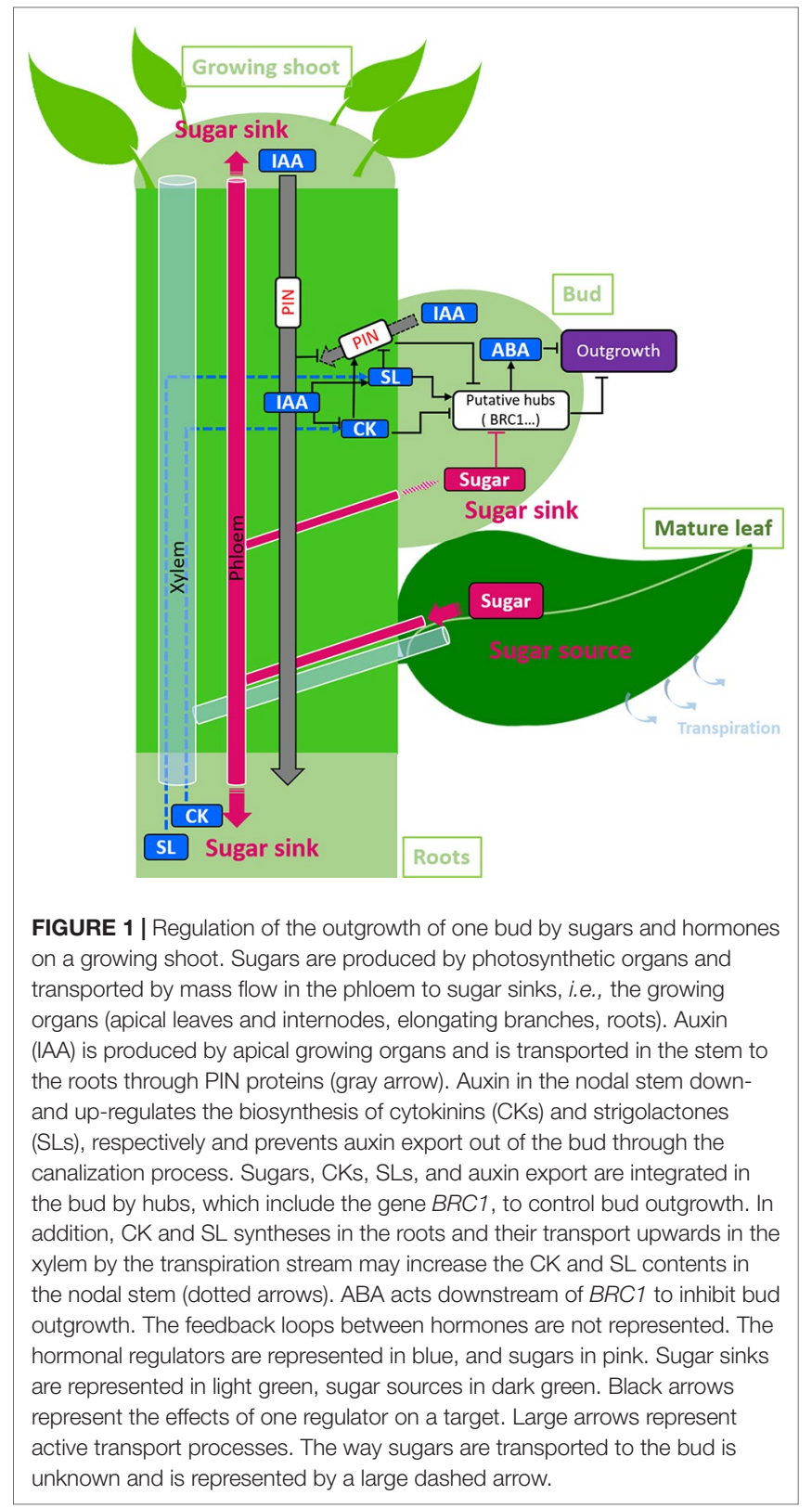

Besides these well-studied auxin-dependent pathways in the vicinity of the bud, some studies have also highlighted the important role of roots as a source of SLs and CKs. They indicate that auxin-related apical dominance in the shoot may be modulated by root-derived CKs and SLs, as a way to adjust apical dominance in the aerial part to soil nutrient status (Kohlen et al., 2011; Muller et al., 2015; Xi et al., 2015). Furthermore, evidences support a main role of root-derived CKs and SLs in regulating the outgrowth pattern along an axis through feedback loops between shoot and root, and SLs, CKs, and auxin (not represented on the figure; Dun et al., 2009b; Ligerot et al., 2017). However, research about the role of long-distant components from buds other than auxin is still scarce, and further work is definitely required to get a more integrated understanding of the hormonal regulation of apical dominance expression in plants. 


\section{BUD OUTGROWTH REGULATION THROUGH COMPETITION FOR NUTRIENTS}

Relationships between the plant nutrient status and the number of new branches arising in a growth period have been suggested for decades. For example, for tree species, the number of new branches was found correlated to the vigor of the parent branch (Heuret et al., 2000). In wheat, the bud outgrowth probability at a given leaf rank on the main stem was correlated to the parent leaf mass per unit area (Bos, 1999; Evers et al., 2006). In ryegrass, the number of tillers that recovered after cutting was strongly correlated to the initial carbohydrate level before cutting (Davies, 1965). These observations led to the intuition that the degree of competition for nutrients within the plant regulates the investment into new branches.

The degree of competition within the plant is a complex variable that depends on nutrient supply to the plant, nutrient transport, storage, and use by the different organs and evolves dynamically with plant development. To address this complexity, different hypotheses related to competition for nutrients in shoot branching were first tested using computational models. The results of these simulations confirmed the plausibility of branching regulation by nutrient competition. These results have been corroborated in recent years by physiological experiments that brought evidence supporting the initial intuition and providing a better understanding of the mechanisms involved.

\section{Computer Models of Branching Regulation by Competition for Nutrients}

The first models were developed for trees and formalized that a limited amount of nutrients is assimilated by the plant and shared among tree branches according to given priority rules, and that the nutrient level in a branch determines the emergence of new branches. Based on the observations of weaker water flow in less vigorous branches as compared to the main trunk (Zimmermann, 1978), 25 years ago, Borchert and Honda implemented a model in which branches were in competition for nutrients coming from the roots through the transpiration stream (Borchert and Honda, 1984). Later, the model LIGNUM initially developed for young pine trees considered that branches were in competition for carbohydrates produced by photosynthesis in tree aerial parts (Perttunen et al., 1996; Perttunen et al., 1998). Competition for nutrients or carbohydrates among branches simulated qualitative observations made on real trees, such as a reduction of branch emergence with tree development or branching stimulation after branch removal by pruning (Borchert and Honda, 1984). Priority rules for nutrient or carbohydrate allocation among branches were essential to simulate observed tree forms (Perttunen et al., 1998; Palubicki et al., 2009). For example, in Borcher and Honda's model, preferential nutrient allocation to a given branch position and to the more vigorous branch (defined by the number of daughter transpirating branches) explained the morphological differentiation of branches into leaders and weaker lateral shoots observed in some species (Borchert and Honda, 1984).

Several years later, the concept emerged that competition for carbohydrates can be represented by the source-sink ratio
(Warren-Wilson, 1972; Lacointe, 2000), which is the balance between the production rate of carbohydrates by photosynthesis and their utilization rate for growth. For grass species, this concept arises in particular from the observed correlations between the tillering level and the balance between (i) PAR intensity, that determines photosynthesis, and (ii) temperature, that determines the organ growth rate (Mitchell, 1953; Bos and Neuteboom, 1998). Based on findings that sugars act as signaling entities on meristematic activity (Sherson et al., 2003; Heyer et al., 2004), the authors of the rice model ecomeristem assumed that sugars also acted as signals in bud outgrowth regulation and that the source-sink ratio was a signal analogous to sugar signaling (Luquet et al., 2006). Supporting the concept, the source-sink ratio dynamics correlated with the dynamics of sugar reserves, an indicator of sugar availability. The authors argued that such a regulating system allowed for the plant to adjust the carbohydrate sinks to the sources: in case of a high sourcesink ratio, plant development is stimulated, thus increasing the sink strength for carbohydrates, which in turn decreases the ratio. This concept has been taken up by other models, e.g., for wheat (Evers et al., 2010) or trees (Letort et al., 2008; Mathieu et al., 2009). Simulations of plant development were validated against quantitative experimental observations for grasses, but the robustness of the models was not demonstrated (Luquet et al., 2006; Evers et al., 2010). For trees, the concept explained observed trends qualitatively, such as a low branch number under low light intensity, or branching rhythmicity as a result of the negative feedback between branch emergence and the source-sink ratio (Letort et al., 2008; Mathieu et al., 2009).

All these studies show that branching regulation by competition for nutrients explains some of the observed plant behaviors in different species. However, the concept was lacking more direct molecular experimental evidence. In the 2010s, several biological experiments, independent of modeling studies, confirmed bud outgrowth regulation by competition for carbohydrates and the involvement of sugar signaling in some species.

\section{Experimental Evidence for Bud Outgrowth Regulation by Competition for Carbohydrates in Grasses and Garden Pea}

A first series of experiments demonstrated that differences in tiller bud outgrowth induced by changes in the source-sink ratio in some grass species were correlated to differences in the bud sugar status. The tin mutant of wheat, which is characterized by earlier internode elongation as compared to the wild type, displayed a reduced number of tillers and over-expression of a sucrosestarvation gene, downregulation of a sucrose-inducible gene, and a reduced sucrose content in the inhibited buds (Kebrom et al., 2012). In sorghum, bud outgrowth inhibition by defoliation was correlated to up- and down-regulations of sucrose starvation and sucrose-inducible genes in buds, respectively (Kebrom and Mullet, 2015). In this case, defoliation of the subtending leaf blade or any other leaf blade inhibited bud outgrowth, indicating that outgrowth may be dependent on the overall plant sugar status, as implemented in models, rather than on sugar supply by the subtending leaf. No similar studies were made in tree species. 
Definitive proof of a role of sugars in bud outgrowth regulation by the source/sink balance was given by Mason et al. (2014) in garden pea. Removal of the apical growing organs by decapitation of the shoot tip led to bud outgrowth and rapid sugar redistribution and accumulation in the outgrowing buds before auxin depletion in the nodal segment adjacent to the outgrowing bud. This phenomenon was abolished by defoliation which reduced sugar supply, while exogenous sucrose supply through the petioles of intact plants (not decapitated or defoliated) released the buds from apical dominance. These behaviors indicate that sugar accumulation in the buds of decapitated plants is both necessary and sufficient for bud outgrowth. Additional proof was given recently by the observation that the elevated sucrose and hexose levels of transgenic plants overexpressing fructose 1,6-bisphosphatase II in the cytosol increased the number of lateral shoots (Otori et al., 2017).

\section{Role of Sugar in Bud Outgrowth Regulation}

Using excised nodal stem segments in vitro to manipulate sugar availability for buds easily, evidence was brought about both the trophic and signaling roles of sugars in bud outgrowth, as demonstrated in other processes of plant development (Moore et al., 2003; Rolland et al., 2006; Lastdrager et al., 2014; Li and Sheen, 2016; Sakr et al., 2018). As compared to an osmotic control, sucrose supply or supply of its derivative hexoses (glucose and fructose) to isolated buds increased sugar levels in buds and stimulated their outgrowth in a dose-dependent manner in species such as rose and garden pea (Henry et al., 2011; Rabot et al., 2012; Barbier et al., 2015; Fichtner et al., 2017). In line with the trophic role of sugars, sugar-induced bud outgrowth in rose was characterized by a higher sugar metabolic activity of the bud linked to increased expression of the sugar transporter RhSUC2 and in the expression and activity of vacuolar invertase RhINV1, an enzyme responsible for sucrose cleavage into hexoses and usually related to organ sink strength (Girault et al., 2010; Henry et al., 2011; Rabot et al., 2012). Interestingly, non-metabolizable sucrose or fructose analogs also induced bud outgrowth in rose (Rabot et al., 2012; Barbier et al., 2015; Wingler, 2018) and stimulated the expression and the activity of the vacuolar invertase RhINV1 (Rabot et al., 2012). This observation supports a scenario in which sugar availability for the bud acts as a signaling entity regulating its outgrowth and its sink strength. This role may be mediated, at least partly, through trehalose-6-phosphate, an important indicator of the carbohydrate status in plants (Figueroa and Lunn, 2016). Sucrose supply to nodal stem segments of garden pea induced a rapid concentrationdependent increase of the trehalose-6-phosphate (Tre6P) content in the buds that was highly correlated with their outgrowth rate (Fichtner et al., 2017). Such a rapid Tre6P increase in outgrowing buds was also observed after removal of the main sink for sugars by decapitation of garden pea shoots. Sugar signal may regulate bud outgrowth through the sucrose non-fermenting kinase 1 (SnRK1) complex, which perceives cell energetic status and regulates growth activity accordingly (Tsai and Gazzarrini, 2014). This supports the concept implemented in models that the source-sink ratio controls a sugar signal that modulates bud outgrowth.

\section{Sugar Interplays With Hormones}

Interplays between sugar and hormonal pathways have been recently reported in bud outgrowth regulation in rose and pea (Barbier et al., 2015; Bertheloot et al., 2019). Bud outgrowth is under an antagonistic coupled control of sugar and auxin levels. While exogenous auxin supply to nodal segments in vitro inhibited bud outgrowth dose-dependently, sugar supply partially removed the inhibitory effect of auxin in a manner that was also dose-dependent. This supports the view that a high plant sugar status may attenuate auxin-mediated apical dominance, leading eventually to bushy phenotypes.

Sugar promoting effect on bud outgrowth was accompanied by a number of changes in the bud outgrowth hormonal network for rose nodal segments in vitro (Barbier et al., 2015). These changes include the simulation of CK biosynthesis and level in the stem and a down-regulation of a SL signaling gene (MAX2). However, CK level in the stem and auxin export from the bud to the stem are unlikely to be the main mediators of sugar promoting effect on bud outgrowth. Without sucrose, CK supply to rose nodal segments in vitro did not induce bud outgrowth, and sucrose could not antagonize the auxin-dependent repression of CK levels in the stem (Barbier et al., 2015; Bertheloot et al., 2019). Sugar-stimulated bud outgrowth was rather related to the impairment of SL response, because exogenously applied SL was inefficient in inhibiting bud outgrowth in the presence of high sugar concentration in rose and pea (Bertheloot et al., 2019). In addition, buds of pea mutants deficient in SL perception displayed a reduced response to changes in sugar supply in vitro. Finally, a computational model, in which auxin regulates bud outgrowth through regulation of the production of CKs and SLs (second messenger model) and sugar acts by suppressing SL response, captured the diversity of observed bud outgrowth responses to sugar and hormones in a quantitative manner. Further studies are required to decipher the exact targets of sugars, but the SL signaling-related gene MAX2 and the integrator gene $B R C 1$ that are downstream of SLs and down-regulated under high sucrose conditions for different species may be involved (Kebrom et al., 2010; Kebrom et al., 2012; Mason et al., 2014; Barbier et al., 2015; Kebrom and Mullet, 2015; Otori et al., 2017).

\section{Summary}

These data highlight that competition for sugars within the plant, indicated by the source/sink ratio, is a key component of branching regulation at least in annual species. As depicted in Figure 1, sugars are produced by source organs, mainly photosynthetically leaves, and transported through the phloem to sink organs such as the shoot growing apical and root zones. High sugar availability in the vicinity of the bud, resulting from high ratio of source to sink activity, promotes bud outgrowth. The exact pathway by which sugar availability regulates bud outgrowth remains to be elucidated, but sugar signaling seems crucial (Rabot et al., 2012; Barbier et al., 2015; Fichtner et al., 2017). Such signaling role of sugar appears as an efficient way to adjust plant development to endogenous resources. New branches, which are highly demanding in resources, are created only if the resource status of the plant is sufficient to sustain their growth. 
Recent studies highlight the existence of an interplay between sugar and the hormonal networks in bud outgrowth regulation; more particularly, high sugar availability antagonizes auxin inhibitory effect through inhibition of SL signaling (Bertheloot et al., 2019). A hormonal role has also been suggested by the simulations of previous nutrient-based models. Indeed, this kind of models could not fully explain branching phenotypes at the plant scale and should be coupled to other signaling processes. We report that Borchert and Honda's and LIGNUM models include priority rules for nutrient allocation among branches, essential to simulate tree branching habits (Borchert and Honda, 1984; Perttunen et al., 1996; Perttunen et al., 1998). Other models have to define which bud is sensitive to carbohydrates to simulate positions of branches on trees (Letort et al., 2008) or the observed coordination between tiller appearance and parent axis development in grasses (Letort et al., 2008; Evers et al., 2010). Sensitivity to carbohydrates also depends on mineral nutrition in grasses (Dingkuhn et al., 2007; Kim et al., 2010a; Kim et al., 2010b; Alam et al., 2014). All these effects may involve hormonal pathways, because hormones are regulated by both plant development and growth conditions. This raises the question of how sugar and hormonal signals are integrated to regulate bud outgrowth in spatial and temporal dynamics at the plant scale.

Contrary to sugars, the role of xylem-transported nutrients in bud outgrowth regulation has been the subject of very few studies. However, they could contribute to bud outgrowth regulation. Amino acids were required for bud outgrowth in nodal segments of rose in vitro (Le Moigne et al., 2018), transgenic lines deficient in amino acids displayed decreased tillering in rice (Funayama et al., 2013; Ohashi et al., 2017; Ohashi et al., 2018), and overexpression of a glutamine synthase gene promoted tillering in sorghum (Urriola and Rathore, 2015). Whether amino acids act as signaling entities in bud outgrowth remains to be investigated.

\section{INTERACTION OF LIGHT WITH THE NETWORK OF ENDOGENOUS REGULATORS}

Besides its role as an energy source for photosynthesis, light is also a powerful environmental signal that controls many developmental processes (de Wit et al., 2016; Gangappa and Botto, 2016; Lee et al., 2017). In particular, it is involved in the shade avoidance syndrome (SAS), characterized by typical morphological changes such as leaf hyponasty, an increase in hypocotyl and internode elongation, and extended petioles, which aim to maximize light interception by the plant for photosynthesis (Franklin, 2008). In bud outgrowth regulation, light also acts as a signal that may prevent a new branch from developing in low light conditions. In accordance with the signaling role of light, a very low light intensity on the bud was sufficient to trigger bud outgrowth in decapitated rose (Girault et al., 2008). Tillering can cease in grasses before the occurrence of a significant reduction in PAR intensity due to canopy closure, but concomitantly with a reduction of the R:FR ratio
(Ballare et al., 1987). Simulation studies support a role of light in shaping plant branching architecture in different species. In trees, the global branching structure can be explained qualitatively by space colonization algorithms, which consider competition for space as the key factor determining the branching structure of the tree (Runions et al., 2007; Palubicki et al., 2009). In herbaceous species, the inhibiting effect of shading or high plant densities can be simulated by regulating bud outgrowth by the local light environment on the apical meristem at the time of bud formation (Gautier et al., 1999; Evers et al., 2007).

At the plant scale, light signaling interacts with hormonal and/or nutrient regulation by controlling the homeostasis, transport, and signaling of hormones and nutrients. Remarkably, light, hormones, and nutrients seem to converge to the same regulating hubs (Quail, 2002; Moore et al., 2003; Lau and Deng, 2012; Li et al., 2017; Mawphlang and Kharshiing, 2017; Sakuraba and Yanagisawa, 2018; Simon et al., 2018). Compared to the endogenous network responsible for apical dominance, relatively few studies have focused on the interaction of light with hormones and nutrients in the control of axillary bud outgrowth. Most studies have focused on the effect of the R:FR ratio, which is a signal of canopy closure. More recently, the effect of light intensity was also investigated.

\section{Interaction of Light With the Hormonal Regulatory Network \\ R:FR Ratio}

Studies were made by directly manipulating light quality or by using phyB Arabidopsis mutants, which are deficient in phytochrome B-mediated red light perception and display a low branching level as compared to the wild-type (Kebrom et al., 2006; Finlayson et al., 2010; Su et al., 2011). Those studies highlight that enhanced ABA biosynthesis in the bud has a main role in the effect of the R:FR ratio on bud outgrowth. The bud outgrowth response to R:FR is negatively correlated to the bud ABA level and to the expression of ABA biosynthesis- and signaling-related genes in different species (Tucker and Mansfield, 1972; GonzalezGrandio et al., 2013; Reddy et al., 2013; Yao and Finlayson, 2015; Kebrom and Mullet, 2016; Gonzalez-Grandio et al., 2017; Holalu and Finlayson, 2017; Tarancon et al., 2017; Yuan et al., 2018). The ABA response was even reported to precede the bud outgrowth response to an increase of the R:FR ratio in Arabidopsis (Holalu and Finlayson, 2017). Furthermore, Arabidopsis mutants deficient in $\mathrm{ABA}$ biosynthesis (nced3-2 and aba2-1) exhibited lower suppression of bud outgrowth by low R:FR than the wild type (Reddy et al., 2013; Yao and Finlayson, 2015). The mechanisms leading to changes in the ABA level involve $B R C 1$. $B R C 1$ induces ABA biosynthesis in buds, is up-regulated by low R:FR or following $p h y B$ mutation, and is involved in low R:FR-dependent branch suppression (Gonzalez-Grandio et al., 2013; Yuan et al., 2018). Low R:FR-induced ABA biosynthesis may repress bud outgrowth partly by reducing bud auxin biosynthesis, since both phyB Arabidopsis mutants and exogenous ABA supply to wildtype plants reduced the expression of an auxin biosynthesis gene within the bud (Finlayson et al., 2010; Yao and Finlayson, 2015). 
Upstream of $B R C 1$, several other regulators of bud outgrowth than ABA could contribute to bud inhibition by low R:FR. Auxin plays a key role in the shade-avoidance syndrome, including the promotion of hypocotyl and petiole growth, leaf hyponasty, and phototropism (Iglesias et al., 2018). In seedlings, low R:FR increases auxin level in the foliage by stimulating its biosynthesis; auxin then moves to the stem where it reaches epidermal tissues through lateral orientation of PIN proteins to drive the auxin flux to the epidermis to promote growth (Iglesias et al., 2018). Similarly, relationships have been observed between auxin and bud outgrowth inhibition in Arabidopsis phyB mutants, which cannot perceive red light. The branching inhibition reported in phyB Arabidopsis mutants was alleviated by disrupting auxin signaling (Finlayson et al., 2010). In this case, branching inhibition was related to elevated auxin sensitivity and signaling in the shoot segments proximal to axillary buds (Reddy and Finlayson, 2014). Low auxin level supply to isolated stem segments inhibited $p h y B$ buds more than wild-type, and phy $B$ shoots displayed elevated auxin-responsive genes expression compared to the wild-type. This obviously raises the question of how auxin- and ABA-mediated pathways interact to regulate bud outgrowth in response to R:FR. Although ABA acts downstream of auxin signaling (Yao and Finlayson, 2015), Holalu and Finlayson (2017) reported that bud response to low R:FR involve changes in bud ABA signaling before any detectable alteration in stem auxin signaling, indicating that $\mathrm{ABA}$ and auxin signalings are part of different R:FR-induced pathways. ABA pathway may be responsible for a rapid response of the bud to R:FR, while auxin signaling in the stem may sustain this rapid response. Low auxin transport rate was also observed in the shoots of phyB mutants but its role in inhibiting bud outgrowth was not demonstrated (Reddy and Finlayson, 2014).

Besides auxin, SL biosynthesis- and signaling-related genes were also found to be up-regulated by low R:FR or by $p h y B$ mutation in chrysanthemum, sorghum, or petunia buds (Kebrom et al., 2010; Drummond et al., 2015; Yuan et al., 2018). Furthermore, bud outgrowth inhibition by phyB mutation was impaired in SL biosynthesis $(\max 4)$ or signaling $(\max 2)$ mutants as compared to wild-type Arabidopsis (Finlayson et al., 2010), indicating a potential role of these genes in low R:FR-dependent bud outgrowth regulation. This is in accordance with the main role of the SL signaling-related gene MAX2 in light-regulated hypocotyl elongation in Arabidopsis seedlings (Shen et al., 2007; Shen et al., 2012; Jia et al., 2014). Future tasks would be to identify the role of MAX2 and understand its relationship with ABA and auxin signaling pathways in bud response to R:FR.

\section{Light Intensity}

The interaction between light intensity and hormonal regulation of bud outgrowth has mainly been investigated in rose. First data indicate that GAs are not sufficient to mimic the promotive effect of light in dark-placed buds (Choubane et al., 2012). For decapitated plants, dark-repressed bud outgrowth correlated with a down-regulation of two GA biosynthesis genes, and light-induced bud outgrowth was inhibited by GA biosynthesis inhibitors, but GA supply to plants in the dark could not rescue bud outgrowth.

Recent experimental studies on rose support a model in which light intensity stimulates CK biosynthesis in the stem, which in turn stimulates bud outgrowth. As compared to darkness or low light intensity, a higher light intensity rapidly and significantly increased the $\mathrm{CK}$ content in the nodal segment bearing the light-stimulated bud (Roman et al., 2016; Corot et al., 2017). This was correlated with rapid up-regulation of genes encoding CK synthesis, transport and signaling, and down-regulation of genes encoding CK degradation (RhCKX1) (Roman et al., 2016). This is in line with the known effect of light on CK biosynthesis, metabolism, and transport in other biological processes (Zubo et al., 2008; Boonman et al., 2009; Zdarska et al., 2015; Janeckova et al., 2018). In addition, local exogenous CK application restored the bud outgrowth ability under non-permissive light conditions (Roman et al., 2016; Corot et al., 2017). Interestingly, studies on the shoot apical meristem in tomato and Arabidopsis also demonstrated the involvement of CKs in the light-induced activity of the apical meristem (Yoshida et al., 2011; Pfeiffer et al., 2016).

Light-induced bud outgrowth may involve the two CK-related processes controlling bud outgrowth: BRC1 repression and PIN up-regulation (which would increase auxin canalization capacity) (Dun et al., 2012; Waldie and Leyser, 2018). Indeed, both light and CK exogenous supply down-regulated $B R C 1$ in the bud and up-regulated PIN1 expression in the stem for rose decapitated plants (Roman et al., 2016). In line with this, light intensity was also reported to down-regulate BRC1 in Arabidopsis (Su et al., 2011). In addition, both light and CKs supply to rose decapitated plants decreased the expression of the SL signaling-related gene MAX2 and up-regulated sugar metabolism-related genes (Djennane et al., 2014; Roman et al., 2016), consistent with the well-known role of CKs on the strength of sink organs (Roitsch and Ehness, 2000; Wang et al., 2016b). For rose intact plants, high light intensity also decreased ABA level in the node adjacent to the bud compared to low light intensity, and $A B A$ exogenous supply to the node could antagonize the promoting effect of CK supply under low light intensity (Corot et al., 2017). All these changes underline the complexity of the regulation, and further research is required to understand the basic mechanism behind the light effect on bud outgrowth.

Besides CKs located in bud vicinity, it is likely that rootderived CKs contribute to bud outgrowth stimulation in response to light intensity. Indeed, the concentration in root-derived CK forms (tZ, tZR, tZRMP) increases in stems and buds in these conditions (Roman et al., 2016; Corot et al., 2017); however, this remains to be demonstrated experimentally.

\section{Interaction of Light With the Nutrient- Based Regulatory Network}

Strong evidence is given about a main role of competition for carbohydrates, indicated by the source-sink ratio, in bud outgrowth regulation in garden pea and grasses (Kebrom et al., 2012; Kebrom and Mullet, 2015). The carbohydrate source-sink ratio may be affected by the plant light environment: a low R:FR ratio enhances stem growth (Demotes-Mainard et al., 2016), a strong sugar sink, and PAR intensity regulates photosynthesis as well as plant aerial morphogenesis and root growth (Granier and Tardieu, 1999; Chenu et al., 2005; Nagel et al., 2006). As proposed in some tillering models (Luquet et al., 2006; Evers et al., 2010) and by Kebrom (2017) and Bertheloot et al. (2019), 
light regulation of source-sink relationships within the plant may modulate sugar availability for buds, leading in turn to reduced auxin-related apical dominance and induction of bud outgrowth. This is supported by studies reporting a negative impact of a low R:FR ratio on the sugar content or on genes related to sugar metabolism and signaling in the bud (Kebrom and Mullet, 2016; Yuan et al., 2018), as well as changes in stem sugar levels in response to light intensity, in ways correlated to bud outgrowth (Lafarge et al., 2010; Furet et al., 2014; Corot et al., 2017). However, the involvement of sugar in the effect of light has not been proved by physiological experiments yet.

Experimental data rather indicate that local sugar availability in the stem or in the bud may not be limiting for bud outgrowth in case of low PAR intensity. In decapitated and defoliated rose plants under white light, preventing light perception by the bud by masking it while leaving the photosynthetic stem under white light maintained the bud inhibited, while applying a photosynthesis inhibitor on the bud did not prevent its outgrowth (Girault et al., 2008; Roman et al., 2016). In addition, local exogenous sugar supply to decapitated shoot stumps under darkness, to the petioles of intact plants under low PAR intensity, or to rose nodal segments cultivated in vitro in darkness did not induce bud outgrowth (Henry et al., 2011; Rabot et al., 2012; Roman et al., 2016; Corot et al., 2017). The activity of isolated apical meristems of Arabidopsis was also prevented by darkness and was not restored by exogenous sugar supply (Yoshida et al., 2011; Pfeiffer et al., 2016; Li et al., 2017). For both apical meristem and axillary buds under limiting light conditions, CKs may be a limiting factor explaining the inability of sugars to promote bud outgrowth locally. CKs could act by limiting the bud sink strength for sugars (Albacete et al., 2014).

\section{Summary}

Experimental studies have revealed an interaction between light and hormonal regulators at the scale of the nodal stem segment and its bud. As illustrated in Figure 2, an increase in light intensity stimulates CK level in the stem, which promotes bud outgrowth, while a low R:FR ratio stimulates ABA synthesis in the bud, leading in turn to rapid bud inhibition, a process that could be reinforced by auxin signaling increase in stem. Besides these main pathways, several other endogenous regulators are impacted by light, such as the SL signaling-related genes or sugars, but their exact role has still to be understood. Evidence coming from rose under darkness or low PAR intensity indicates that stem sugars in the vicinity of the bud are not a locally limiting factor of bud outgrowth in these particular light conditions. Literature data on nodal stem segments in vitro rather indicate that light intensity and sugars may have a synergetic effect on bud outgrowth (Henry et al., 2011; Rabot et al., 2012; Rabot et al., 2014), as reported for the activity of the apical meristem (Li et al., 2017). This leads to the idea that the light lock should be lifted for a high sugar status of the shoot to stimulate bud outgrowth. Additional studies are also required to understand the role of elevated sugar levels in other plant parts than the stem segment bearing the bud in bud outgrowth. For example, sugars regulate nitrogen uptake by the roots (Lejay et al., 2003; Lejay et al., 2008) or hormone biosynthesis (Sakr et al., 2018), which may also indirectly impact bud outgrowth.

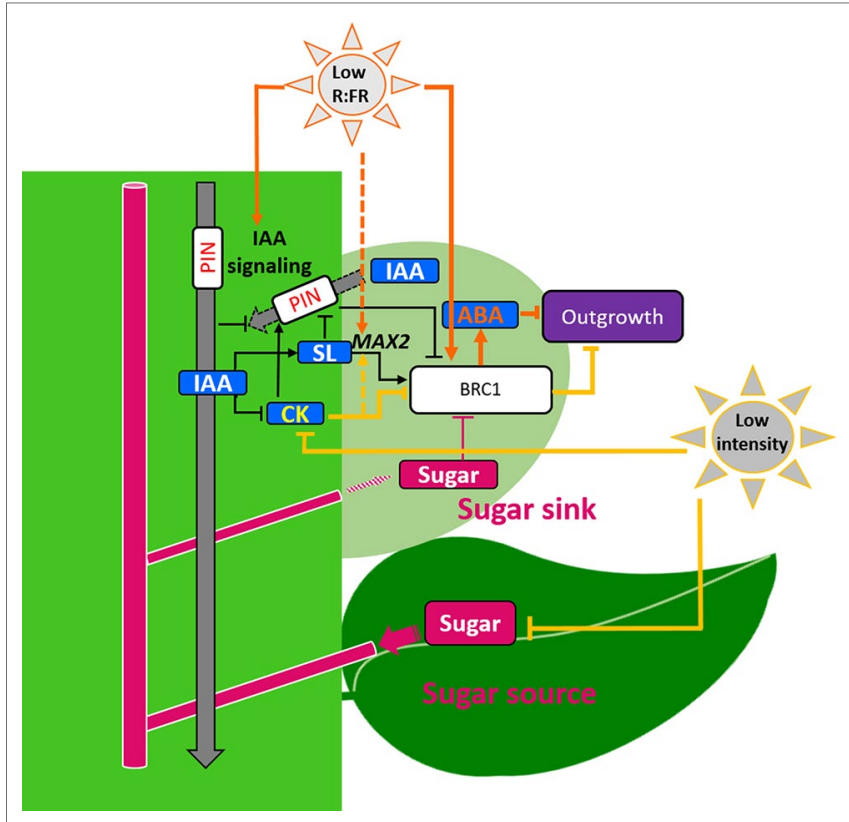

FIGURE 2 | Interaction of light intensity and the R:FR ratio with the endogenous regulators of bud outgrowth. A low R:FR ratio stimulates $A B A$ production in the bud, which inhibits bud outgrowth, a phenomenon that is reinforced later on by auxin signaling stimulation through an unknown mechanism (solid dark orange arrows and text); low R:FR also up-regulates the SL signaling-related gene MAX2 (dotted dark orange arrows), but the contribution of these changes to bud outgrowth regulation by the $\mathrm{R}$ :FR ratio is not known yet. Low light intensity reduces CK contents in the nodal stem by reducing the expression of CK synthesis genes and increasing that of $\mathrm{CK}$ degradation genes, which inhibits bud outgrowth (solid light orange arrows and text) and up-regulates MAX2 but the contribution of this change to bud inhibition by low light intensity is not known yet (dotted light orange arrows and text); low light intensity also decreases the sugar content, but this is not a main limiting factor in the undertaken studies. For color and arrow significations, see also Figure 1.

\section{DISCUSSION}

Light signaling modulates plant involvement in lateral branching by controlling the release of axillary buds from apical dominance. So far, studies mainly conducted on annuals have provided an almost complete picture of the intricate hormonal regulatory network involved in apical dominance, regardless of environmental factors (Figure 1). In particular, great progress has been made since the 2000s with the discovery of SL mutants and of the role of PIN proteins. The development of simulation tools made it easier to investigate complex regulations like those related to the canalization theory or to the SL molecular network, both involving feedbacks (Domagalska and Leyser, 2011). The demonstration that the degree of competition for sugars within the plant regulates bud outgrowth is more recent (Mason et al., 2014) despite first assumptions supported by computer modeling (Luquet et al., 2006; Mathieu et al., 2009). Recent evidences of interplays between sugar and hormones further complicate bud outgrowth regulating network. In addition, the main branching-related hormones display dose-dependent effects on bud outgrowth (Chatfield et al., 2000; Dun et al., 2012; Barbier et al., 2015; Corot et al., 2017) and other compounds may 
take a part in this mechanistic complexity, including reactive oxygen species (ROS) (Chen et al., 2016; Signorelli et al., 2018). For instance, $\mathrm{H}_{2} \mathrm{O}_{2}$-dependent bud outgrowth inhibition may be linked to promotion of auxin biosynthesis in the apex which inhibits CK biosynthesis in the stem in tomato (Chen et al., 2016). The presence of different regulators quantitatively regulating bud outgrowth raises the question of their integration within the bud. BRC1 plays certainly a key role, but some regulations also occur through BRC1independent pathways (Minakuchi et al., 2010; Braun et al., 2012; Wang et al., 2019). Recently, studies indicate that integration could be done in the regulation of carbon metabolism of the bud (Tarancon et al., 2017; Martin-Fontecha et al., 2018).

Although the major role of light intensity and quality in branching regulation has been known for decades, knowledge about the interaction between light and the endogenous regulators of bud outgrowth emerged only recently. The current knowledge (Figure 2) indicates that (i) light intensity stimulates production of CKs (inducer of bud outgrowth) in the nodal stem segment and (ii) a low R:FR ratio stimulates production of ABA (inhibitor of bud outgrowth) in the bud, and this process seems to be later reinforced by an increase in auxin signaling in the stem. This knowledge remains however very fragmented and does not provide a comprehensive understanding of bud outgrowth regulation at the scale of the plant, as discussed below.

First, knowledge is missing about light interaction with other endogenous regulators close to the bud. Indeed, light impacts sugar level and SL signaling (Finlayson et al., 2010; Kebrom and Mullet, 2016; Roman et al., 2016; Corot et al., 2017), which raises the question whether these different regulators act or not in the same pathway. Second, no study has addressed the question of the role of light effects on organs located at distance from buds. Light induces changes in plant growth (Granier and Tardieu, 1999; Nagel et al., 2006; Kebrom, 2017) that may alter the competition for carbohydrates within the plant and the availability of sugar for bud outgrowth. Light modulation of plant growth may also induce changes in hormone metabolism, signaling, and transport, and thereby hormone distribution and quantities. Understanding all these changes is necessary for building a comprehensive picture of light effect on bud outgrowth. Third, light regulation of bud outgrowth pattern at the scale of an axis is unknown. Light was reported to influence the number of outgrowing buds and the time between successive outgrowths (Demotes-Mainard et al., 2013; Corot et al., 2017). Future tasks would be to investigate whether light effect could result from heterogeneous distribution of the different regulators along the axis and from a temporal feedback loop by which outgrowing buds modify the regulator levels in the vicinity of the remainder buds, maintaining them dormant. However, different sensitivities of the buds to their local regulators, due to bud age, light history for example, may obviously complicate bud outgrowth regulation at axis level.

All these elements highlight the complexity of lightmediated bud outgrowth regulation at the plant scale. In recent years, the use of modeling has become prevalent to gain insight into the complex regulation of developmental processes by both endogenous and exogenous processes.
These models, combining biological process description with an explicit computational description of the plant biological structure, called functional-structural plant models (FSPM), have proved meaningful to address the complexity of developmental systems as a collection of interacting constituents (at molecular or cellular level for example). FSPMs make it possible to identify and test various hypotheses on the local interaction rules and to compare qualitatively and quantitatively, with the experiments, the result emerging from these simulated interactions at an integrated level. This approach has been successfully used in the last decade to study various aspects of plant development such as flowering and inflorescence architecture development (Prusinkiewicz et al., 2007; Wenden et al., 2009), phyllotaxis (de Reuille et al., 2006; Jonsson et al., 2006; Smith et al., 2006; Refahi et al., 2016), the role of mechanics in morphogenesis (Alim et al., 2012; Boudon et al., 2015; Bozorg et al., 2016). In the study of branching regulation as well, these models have been used to help deciphering the complexity of associated regulation networks and branching processes (Evers and Vos, 2013)-for example, in the analysis of the competition for sugars (Luquet et al., 2006), auxin regulation of bud outgrowth (Prusinkiewicz et al., 2009), auxin transport in mosses (Coudert et al., 2015), and sugar interplay with auxin (Bertheloot et al., 2019). Likewise, approaches combining quantitative experimental observations and computer simulations in FSPMs are thus expected to be instrumental in providing new insights into light interplay with sugar and hormones network in bud outgrowth regulation at the plant scale. In particular, to investigate bud outgrowth regulation with FSPM, carbon/sugar fluxes formalism will have to be coupled to a formalization of hormonal functioning, as well as with a representation of the root compartment.

\section{AUTHOR CONTRIBUTIONS}

AS, CG, FB, SD-M, SS, and JB searched for articles, synthetized them, and wrote parts of the review; SS gave the initial impetus for writing a review around light, bud outgrowth, and plant physiology; CG and JB structured the review; JB directed the work.

\section{FUNDING}

This review was conducted in the framework of a $\mathrm{PhD}$ thesis funded by the Environment and Agronomy department of the French National Institute for Agricultural Research (INRA), the French Region Pays de la Loire, and the program "Objectif Végétal, Research, Education and Innovation in Pays de la Loire" (supported by the Region Pays de la Loire, Angers Loire Métropole, and the European Regional Development Fund).

\section{ACKNOWLEDGMENT}

We thank PAIGE team (UMR IRHS) for the administrative work and Annie Buchwalter for reviewing the paper for English usage. 


\section{REFERENCES}

Agharkar, M., Zhang, H., and Altpeter, F. (2007). Generation and characterization of bahiagrass (Paspalum notatum flugge) over-expressing a gibberellincatabolizing enzyme. In Vitro Cell. Dev. Biol.-Animal 43, S56-S56.

Alam, M. M., Hammer, G. L., van Oosterom, E. J., Cruickshank, A. W., Hunt, C. H., and Jordan, D. R. (2014). A physiological framework to explain genetic and environmental regulation of tillering in sorghum. New Phytol. 203 (1), 155167. doi: 10.1111/nph.12767

Albacete, A., Cantero-Navarro, E., Balibrea, M. E., Grosskinsky, D. K., Gonzalez, M. D., Martinez-Andujar, C., et al. (2014). Hormonal and metabolic regulation of tomato fruit sink activity and yield under salinity. J. Exp. Bot. 65 (20), 60816095. doi: 10.1093/jxb/eru347

Alim, K., Hamant, O., and Boudaoud, A. (2012). Regulatory role of cell division rules on tissue growth heterogeneity. Front. Plant Sci. 3, 174. doi: 10.3389/ fpls.2012.00174

Arend, M., Schnitzler, J. P., Ehlting, B., Hansch, R., Lange, T., Rennenberg, H., et al. (2009). Expression of the Arabidopsis mutant abil gene alters abscisic acid sensitivity, stomatal development, and growth morphology in gray poplars. Plant Physiol. 151 (4), 2110-2119. doi: 10.1104/pp.109.144956

Arora, R., Rowland, L. J., and Tanino, K. (2003). Induction and release of bud dormancy in woody perennials: a science comes of age. Hortscience 38 (5), 911-921. doi: 10.21273/HORTSCI.38.5.911

Balla, J., Kalousek, P., Reinohl, V., Friml, J., and Prochazka, S. (2011). Competitive canalization of PIN-dependent auxin flow from axillary buds controls pea bud outgrowth. Plant J. 65 (4), 571-577. doi: 10.1111/j.1365-313X.2010.04443.x

Balla, J., Medved'ova, Z., Kalousek, P., Matijescukova, N., Friml, J., Reinohl, V., et al. (2016). Auxin flow-mediated competition between axillary buds to restore apical dominance. Sci. Rep. 6, 35955. doi: 10.1038/srep35955

Ballare, C. L., Sanchez, R. A., Scopel, A. L., Casal, J. J., and Ghersa, C. M. (1987). Early detection of neighbor plants by phytochrome perception of spectral changes in reflected sunlight. Plant Cell Environ. 10 (7), 551-557. doi: 10.1111/ j.1365-3040.1987.tb01835.x

Bangerth, F. (1994). Response of cytokinin concentration in the xylem exudate of bean (phaseolus-vulgaris l) plants to decapitation and auxin treatment, and relationship to apical dominance. Planta 194 (3), 439-442. doi: 10.1007/BF00197546

Barbier, F., Peron, T., Lecerf, M., Perez-Garcia, M. D., Barriere, Q., Rolcik, J., et al. (2015). Sucrose is an early modulator of the key hormonal mechanisms controlling bud outgrowth in Rosa hybrida. J. Exp. Bot. 66 (9), 2569-2582. doi: 10.1093/jxb/erv047

Barbier, F. F., Dun, E. A., Kerr, S. C., Chabikwa, T. G., and Beveridge, C. A. (2019). An update on the signals controlling shoot branching. Trends Plant Sci. 24 (3), 220-236. doi: 10.1016/j.tplants.2018.12.001

Barthelemy, D., and Caraglio, Y. (2007). Plant architecture: a dynamic, multilevel and comprehensive approach to plant form, structure and ontogeny. Ann. Bot. 99 (3), 375-407. doi: 10.1093/aob/mcl260

Bennett, T., Sieberer, T., Willett, B., Booker, J., Luschnig, C., and Leyser, O. (2006). The Arabidopsis MAX pathway controls shoot branching by regulating auxin transport. Curr. Biol. 16 (6), 553-563. doi: 10.1016/j.cub.2006.01.058

Bertheloot, J., Barbier, F., Boudon, F., Perez-Garcia, M. D., Péron, T., Citerne, et al. (2019). Sugar availability suppresses the auxin-induced strigolactone pathway to promote bud outgrowth. New Phytologist. doi: 10.1111/nph.16201

Beveridge, C. A. (2000). Long-distance signalling and a mutational analysis of branching in pea. Plant Growth Regul. 32 (2-3), 193-203. doi: 10.1023/A:1010718020095

Beveridge, C. A. (2006). Axillary bud outgrowth: sending a message. Curr. Opin. Plant Biol. 9 (1), 35-40. doi: 10.1016/j.pbi.2005.11.006

Booker, J., Chatfield, S., and Leyser, O. (2003). Auxin acts in xylem-associated or medullary cells to mediate apical dominance. Plant Cell 15 (2), 495-507. doi: 10.1105/tpc.007542

Boonman, A., Prinsen, E., Voesenek, L., and Pons, T. L. (2009). Redundant roles of photoreceptors and cytokinins in regulating photosynthetic acclimation to canopy density. J. Exp. Bot. 60 (4), 1179-1190. doi: 10.1093/jxb/ern364

Borchert, R., and Honda, H. (1984). Control of development in the bifurcating branch system of tabebuia-rosea-a computer-simulation. Bot. Gazette 145 (2), 184-195. doi: 10.1086/337445

Bos, H. J. (1999). Plant morphology, envrionment, and leaf area growth in wheat and maize. Wageningen $\mathrm{UR}: \mathrm{PhD}$ thesis.
Bos, H. J., and Neuteboom, J. H. (1998). Morphological analysis of leaf and tiller number dynamics of wheat (Triticum aestivum L.): responses to temperature and light intensity. Ann. Bot. 81 (1), 131-139. doi: 10.1006/anbo.1997.0531

Boudon, F., Chopard, J., Ali, O., Gilles, B., Hamant, O., Boudaoud, A., et al. (2015). A computational framework for $3 \mathrm{~d}$ mechanical modeling of plant morphogenesis with cellular resolution. PloS Comput. Biol. 11 (1), e1003950. doi: 10.1371/journal.pcbi.1003950

Bouguyon, E., Gojon, A., and Nacry, P. (2012). Nitrate sensing and signaling in plants. Semin. Cell Dev. Biol. 23 (6), 648-654. doi: 10.1016/j.semcdb.2012.01.004

Bozorg, B., Krupinski, P., and Jonsson, H. (2016). A continuous growth model for plant tissue. Physical Biol. 13 (6), 065,002. doi: 10.1088/1478-3975/13/6/065002

Braun, N., de Saint Germain, A., Pillot, J. P., Boutet-Mercey, S., Dalmais, M., Antoniadi, I., et al. (2012). The pea TCP transcription factor PsBRC1 acts downstream of strigolactones to control shoot branching. Plant Physiol. 158 (1), 225-238. doi: 10.1104/pp.111.182725

Buskila, Y., Sela, N., Teper-Bamnolker, P., Tal, I., Shani, E., Weinstain, R., et al. (2016). Stronger sink demand for metabolites supports dominance of the apical bud in etiolated growth. J. Exp. Bot. 67 (18), 5495-5508. doi: 10.1093/jxb/erw315

Chabikwa, T. G., Brewer, P. B., and Beveridge, C. (2019). Initial bud outgrowth occurs independent of auxin flow out of buds. Plant Physiol. 179 (1), 55-65 doi: 10.1104/pp.18.00519

Chatfield, S. P., Stirnberg, P., Forde, B. G., and Leyser, O. (2000). The hormonal regulation of axillary bud growth in Arabidopsis. Plant J. 24 (2), 159-169. doi: 10.1046/j.1365-313x.2000.00862.x

Chen, X. J., Xia, X. J., Guo, X., Zhou, Y. H., Shi, K., Zhou, J., et al. (2016). Apoplastic $\mathrm{H} 2 \mathrm{O} 2$ plays a critical role in axillary bud outgrowth by altering auxin and cytokinin homeostasis in tomato plants. New Phytol. 211 (4), 1266-1278. doi: $10.1111 /$ nph. 14015

Chenu, K., Franck, N., Dauzat, J., Barczi, J. F., Rey, H., and Lecoeur, J. (2005). Integrated responses of rosette organogenesis, morphogenesis and architecture to reduced incident light in Arabidopsis thaliana results in higher efficiency of light interception. Funct. Plant Biol. 32 (12), 1123-1134. doi: 10.1071/FP05091

Choubane, D., Rabot, A., Mortreau, E., Legourrierec, J., Peron, T., Foucher, F., et al. (2012). Photocontrol of bud burst involves gibberellin biosynthesis in Rosa sp. J. Plant Physiol. 169 (13), 1271-1280. doi: 10.1016/j.jplph.2012.04.014

Cline, M. G. (1994). The role of hormones in apical dominance-new approaches to an old problem in plant development. Physiol. Plant. 90 (1), 230-237. doi: 10.1034/j.1399-3054.1994.900133.x

Cline, M. G. (1996). Exogenous auxin effects on lateral bud outgrowth in decapitated shoots. Ann. Bot. 78 (2), 255-266. doi: 10.1006/anbo.1996.0119

Cline, M. G., and Oh, C. (2006). A reappraisal of the role of abscisic acid and its interaction with auxin in apical dominance. Ann. Bot. 98 (4), 891-897. doi: 10.1093/aob/mcl173

Cochetel, N., Meteier, E., Merlin, I., Hevin, C., Pouvreau, J. B., Coutos-Thevenot, P., et al. (2018). Potential contribution of strigolactones in regulating scion growth and branching in grafted grapevine in response to nitrogen availability. J. Exp. Bot. 69 (16), 4099-4112. doi: 10.1093/jxb/ery206

Corot, A., Roman, H., Douillet, O., Autret, H., Perez-Garcia, M. D., Citerne, S., et al. (2017). Cytokinins and abscisic acid act antagonistically in the regulation of the bud outgrowth pattern by light intensity. Front. Plant Sci. 8, 1724. doi: 10.3389/fpls.2017.01724

Coudert, Y., Palubicki, W., Ljung, K., Novak, O., Leyser, O., and Harrison, C. J. (2015). Three ancient hormonal cues co-ordinate shoot branching in a moss. ELife 4, e06808. doi: 10.7554/eLife.06808

Crawford, S., Shinohara, N., Sieberer, T., Williamson, L., George, G., Hepworth, J., et al. (2010). Strigolactones enhance competition between shoot branches by dampening auxin transport. Development 137 (17), 2905-2913. doi: 10.1242/ dev.051987

Davies, A. (1965). Carbohydrate levels and regrowth in perennial rye-grass. J. Agricultural Sci. 65, 213. doi: 10.1017/S0021859600083945

de Jong, M., George, G., Ongaro, V., Williamson, L., Willetts, B., Ljung, K., et al. (2014). Auxin and strigolactone signaling are required for modulation of Arabidopsis shoot branching by nitrogen supply. Plant Physiol. 166 (1), 384U549. doi: 10.1104/pp.114.242388

de Reuille, P. B., Bohn-Courseau, I., Ljung, K., Morin, H., Carraro, N., Godin, C., et al. (2006). Computer simulations reveal properties of the cell-cell signaling network at the shoot apex in Arabidopsis. Proc. Natl. Acad. Sci. U. S. A. 103 (5), 1627-1632. doi: 10.1073/pnas.0510130103 
de Wit, M., Keuskamp, D. H., Bongers, F. J., Hornitschek, P., Gommers, C. M. M., Reinen, E., et al. (2016). Integration of phytochrome and cryptochrome signals determines plant growth during competition for light. Curr. Biol. 26 (24), 3320-3326. doi: 10.1016/j.cub.2016.10.031

Demotes-Mainard, S., Huché-Thélier, L., Morel, P., Boumaza, R., Guérin, V., and Sakr, S. (2013). Temporary water restriction or light intensity limitation promotes branching in rosebush. Sci. Hortic. 150, 432-440. doi: 10.1016/j. scienta.2012.12.005

Demotes-Mainard, S., Peron, T., Corot, A., Bertheloot, J., Le Gourrierec, J., Pelleschi-Travier, S., et al. (2016). Plant responses to red and far-red lights, applications in horticulture. Environ. Exp. Botany 121, 4-21. doi: 10.1016/j. envexpbot.2015.05.010

Dingkuhn, M., Luquet, D., Clement-Vidal, A., Tambour, L., Kim, H. K., and Song, Y. H. (2007). "Scale and Complexity in Plant Systems Research: Gene-PlantCrop Relations," in Is plant growth driven by sink regulation?. Eds. Spiertz, J. H. J., Struik, P. C., and VanLaar, H. H., Springer-Verlag GmbH 157-170. doi: 10.1007/1-4020-5906-X_13

Djennane, S., Hibrand-Saint Oyant, L., Kawamura, K., Lalanne, D., Laffaire, M., Thouroude, T., et al. (2014). Impacts of light and temperature on shoot branching gradient and expression of strigolactone synthesis and signalling genes in rose. Plant Cell Environ. 37 (3), 742-757. doi: 10.1111/pce.12191

Domagalska, M. A., and Leyser, O. (2011). Signal integration in the control of shoot branching. Nat. Rev. Mol. Cell Biol. 12 (4), 211-221. doi: 10.1038/nrm3088

Drummond, R. S. M., Janssen, B. J., Luo, Z. W., Oplaat, C., Ledger, S. E., Wohlers, M. W., et al. (2015). Environmental control of branching in petunia. Plant Physiol. 168 (2), 735-73+. doi: 10.1104/pp.15.00486

Drummond, R. S. M., Martinez-Sanchez, N. M., Janssen, B. J., Templeton, K. R., Simons, J. L., Quinn, B. D., et al. (2009). Petunia hybrida carotenoid cleavage dioxygenase7 is involved in the production of negative and positive branching signals in petunia. Plant Physiol. 151 (4), 1867-1877. doi: 10.1104/pp.109.146720

Dun, E. A., Brewer, P. B., and Beveridge, C. A. (2009a). Strigolactones: discovery of the elusive shoot branching hormone. Trends Plant Sci. 14 (7), 364-372. doi: 10.1016/j.tplants.2009.04.003

Dun, E. A., de Saint Germain, A., Rameau, C., and Beveridge, C. A. (2012). Antagonistic action of strigolactone and cytokinin in bud outgrowth control. Plant Physiol. 158 (1), 487-498. doi: 10.1104/pp.111.186783

Dun, E. A., Hanan, J., and Beveridge, C. A. (2009b). Computational modeling and molecular physiology experiments reveal new insights into shoot branching in pea. Plant Cell 21 (11), 3459-3472. doi: 10.1105/tpc.109.069013

Eliasson, L. (1975). Effect of indoleacetic-acid on abscisic-acid level in stem tissue. Physiol. Plant. 34 (2), 117-120. doi: 10.1111/j.1399-3054.1975.tb03803.x

Everatbourbouloux, A. (1982). Transport and metabolism of labeled abscisic-acid in broad-bean plants (VICIA-FABA L). Physiol. Plant. 54 (4), 431-439. doi: 10.1111/j.1399-3054.1982.tb00704.x

Everatbourbouloux, A., and Charnay, D. (1982). Endogenous abscisic-acid levels in stems and axillary buds of intact or decapitated broad-bean plants (VICIA-FABA L). Physiol. Plant. 54 (4), 440-445. doi: 10.1111/j.1399-3054.1982.tb00705.x

Evers, J. B., and Vos, J. (2013). Modeling branching in cereals. Front. Plant Sci. 4, 399. doi: 10.3389/fpls.2013.00399

Evers, J. B., Vos, J., Andrieu, B., and Struik, P. C. (2006). Cessation of tillering in spring wheat in relation to light interception and red: Far-red ratio. Ann. Bot 97 (4), 649-658. doi: 10.1093/aob/mcl020

Evers, J. B., Vos, J., Chelle, M., Andrieu, B., Fournier, C., and Struik, P. C. (2007). Simulating the effects of localized red: far-red ratio on tillering in spring wheat (Triticum aestivum) using a three-dimensional virtual plant model. New Phytol. 176 (2), 325-336. doi: 10.1111/j.1469-8137.2007.02168.x

Evers, J. B., Vos, J., Yin, X., Romero, P., van der Putten, P. E. L., and Struik, P. C. (2010). Simulation of wheat growth and development based on organ-level photosynthesis and assimilate allocation. J. Exp. Bot. 61 (8), 2203-2216. doi: $10.1093 /$ jxb/erq025

Fichtner, F., Barbier, F., Feil, R., Watanabe, M., Annunziata, M. G., Chabikwa, T. G., et al. (2017). Trehalose 6-phosphate is involved in triggering axillary bud outgrowth in garden pea (Pisum sativum L.). Plant J. 92 (4), 611-623. doi: $10.1111 /$ tpj. 13705

Figueroa, C. M., and Lunn, J. E. (2016). A Tale of Two Sugars: Trehalose 6-Phosphate and Sucrose(1 OPEN ). Plant Physiol. 172 (1), 7-27. doi: 10.1104/ pp.16.00417
Finlayson, S. A., Krishnareddy, S. R., Kebrom, T. H., and Casal, J. J. (2010). Phytochrome regulation of branching in Arabidopsis. Plant Physiol. 152 (4), 1914-1927. doi: 10.1104/pp.109.148833

Foo, E., Buillier, E., Goussot, M., Foucher, F., Rameau, C., and Beveridge, C. A. (2005). The branching gene RAMOSUS1 mediates interactions among two novel signals and auxin in pea. Plant Cell 17 (2), 464-474. doi: 10.1105/tpc.104.026716

Foo, E., Morris, S. E., Parmenter, K., Young, N., Wang, H. T., Jones, A., et al. (2007). Feedback regulation of xylem cytokinin content is conserved in pea and Arabidopsis. Plant Physiol. 143 (3), 1418-1428. doi: 10.1104/pp.106.093708

Franklin, K. A. (2008). Shade avoidance. New Phytol. 179 (4), 930-944. doi: 10.1111/j.1469-8137.2008.02507.x

Funayama, K., Kojima, S., Tabuchi-Kobayashi, M., Sawa, Y., Nakayama, Y., Hayakawa, T., et al. (2013). Cytosolic glutamine synthetase $1 ; 2$ is responsible for the primary assimilation of ammonium in rice roots. Plant Cell Physiol. 54 (6), 934-943. doi: 10.1093/pcp/pct046

Furet, P. M., Lothier, J., Demotes-Mainard, S., Travier, S., Henry, C., Guerin, V., et al. (2014). Light and nitrogen nutrition regulate apical control in Rosa hybrida L. J. Plant Physiol. 171 (5), 7-13. doi: 10.1016/j.jplph.2013.10.008

Gangappa, S. N., and Botto, J. F. (2016). The multifaceted roles of HY5 in plant growth and development. Mol. Plant 9 (10), 1353-1365. doi: 10.1016/j. molp.2016.07.002

Gautier, H., Varlet-Grancher, C., and Hazard, L. (1999). Tillering responses to the light environment and to defoliation in populations of perennial ryegrass (Lolium perenne L.) selected for contrasting leaf length. Ann. Bot. 83 (4), 423429. doi: 10.1006/anbo.1998.0840

Girault, T., Abidi, F., Sigogne, M., Pelleschi-Travier, S., Boumaza, R., Sakr, S., et al. (2010). Sugars are under light control during bud burst in Rosa sp. Plant Cell Environ. 33, 1339-1350. doi: 10.1111/j.1365-3040.2010.02152.x

Girault, T., Bergougnoux, V., Combes, D., Viemont, J., and Leduc, N. (2008). Light controls shoot meristem organogenic activity and leaf primordia growth during bud burst in Rosa sp. Plant Cell Environ. 31, 1534-1544. doi: 10.1111/j.1365-3040.2008.01856.x

Gocal, G. F. W., Pharis, R. P., Yeung, E. C., and Pearce, D. (1991). Changes after decapitation in concentrations of indole-3-acetic-acid and abscisic-acid in the larger axillary bud of Phaseolus vulgaris L. cv tender green. Plant Physiol. 95 (2), 344-350. doi: 10.1104/pp.95.2.344

Gomez-Roldan, V., Fermas, S., Brewer, P. B., Puech-Pages, V., Dun, E. A., Pillot, J. P., et al. (2008). Strigolactone inhibition of shoot branching. Nature 455 (7210), 189-U122. doi: 10.1038/nature07271

Gonzalez-Grandio, E., Pajoro, A., Franco-Zorrilla, J. M., Tarancon, C., Immink, R. G. H., and Cubas, P. (2017). Abscisic acid signaling is controlled by a BRANCHED1/HD-ZIP I cascade in Arabidopsis axillary buds. Proc. Natl. Acad. Sci. U. S. A. 114 (2), E245-E254. doi: 10.1073/pnas.1613199114

Gonzalez-Grandio, E., Poza-Carrion, C., Sorzano, C. O. S., and Cubas, P. (2013). BRANCHED1 Promotes axillary bud dormancy in response to shade in Arabidopsis. Plant Cell 25 (3), 834-850. doi: 10.1105/tpc.112.108480

Granier, C., and Tardieu, F. (1999). Leaf expansion and cell division are affected by reducing absorbed light before but not after the decline in cell division rate in the sunflower leaf. Plant Cell Environ. 22 (11), 1365-1376. doi: 10.1046/j.1365-3040.1999.00497.x

Guan, J. C., Koch, K. E., Suzuki, M., Wu, S., Latshaw, S., Petruff, T., et al. (2012). Diverse roles of strigolactone signaling in maize architecture and the uncoupling of a branching-specific subnetwork. Plant Physiol. 160 (3), $1303-$ 1317. doi: $10.1104 /$ pp. 112.204503

Ha, C. V., Leyva-Gonzalez, M. A., Osakabe, Y., Tran, U. T., Nishiyama, R., Watanabe, Y., et al. (2014). Positive regulatory role of strigolactone in plant responses to drought and salt stress. Proc. Natl. Acad. Sci. U. S. A. 111 (2), 851856. doi: 10.1073/pnas.1322135111

Hartmann, A., Senning, M., Hedden, P., Sonnewald, U., and Sonnewald, S. (2011). Reactivation of meristem activity and sprout growth in potato tubers require both cytokinin and gibberellin. Plant Physiol. 155 (2), 776-796. doi: 10.1104/ pp. 110.168252

Hayward, A., Stirnberg, P., Beveridge, C., and Leyser, O. (2009). Interactions between auxin and strigolactone in shoot branching control. Plant Physiol. 151 (1), 400-412. doi: 10.1104/pp.109.137646

Henry, C., Rabot, A., Laloi, M., Mortreau, E., Sigogne, M., Leduc, N., et al. (2011). Regulation of RhSUC2, a sucrose transporter, is correlated with the light 
control of bud burst in Rosa sp. Plant Cell Environ. 34 (10), 1776-1789. doi: 10.1111/j.1365-3040.2011.02374.x

Heuret, P., BarthTlTmy, D., Nicolini, E., and Atger, C. (2000). Analysis of height growth factors and trunk development in the sessile oak, Quercus petraea (Matt.) Liebl. (Fagaceae) in dynamic sylviculture. Can. J. Bot.-Revue Can. Bot. 78 (3), 361-373. doi: 10.1139/b00-012

Heyer, A. G., Raap, M., Schroeer, B., Marty, B., and Willmitzer, L. (2004). Cell wall invertase expression at the apical meristem alters floral, architectural, and reproductive traits in Arabidopsis thaliana. Plant J. 39 (2), 161-169. doi: 10.1111/j.1365-313X.2004.02124.x

Holalu, S. V., and Finlayson, S. A. (2017). The ratio of red light to far red light alters Arabidopsis axillary bud growth and abscisic acid signalling before stem auxin changes. J. Exp. Bot. 68 (5), 943-952. doi: 10.1093/jxb/erw479

Iglesias, M. J., Sellaro, R., Zurbriggen, M. D., and Casal, J. J. (2018). Multiple links between shade avoidance and auxin networks. J. Exp. Bot. 69 (2), 213-228. doi: $10.1093 /$ jxb/erx295

Ito, S., Yamagami, D., and Asami, T. (2018). Effects of gibberellin and strigolactone on rice tiller bud growth. J. Pesticide Sci. 43 (3-4), 220-223. doi: 10.1584/ jpestics.D18-013

Ito, S., Yamagami, D., Umehara, M., Hanada, A., Yoshida, S., Sasaki, Y., et al. (2017). Regulation of strigolactone biosynthesis by gibberellin signaling. Plant Physiol. 174 (2), 1250-1259. doi: 10.1104/pp.17.00301

Janeckova, H., Husickova, A., Ferretti, U., Prcina, M., Pilarova, E., Plackova, L., et al. (2018). The interplay between cytokinins and light during senescence in detached Arabidopsis leaves. Plant Cell Environ. 41 (8), 1870-1885. doi: 10.1111/ pce. 13329

Jia, K. P., Luo, Q., He, S. B., Lu, X. D., and Yang, H. Q. (2014). Strigolactone-regulated hypocotyl elongation is dependent on cryptochrome and phytochrome signaling pathways in Arabidopsis. Mol. Plant 7 (3), 528-540. doi: 10.1093/mp/sst093

Jonsson, H., Heisler, M. G., Shapiro, B. E., Meyerowitz, E. M., and Mjolsness, E. (2006). An auxin-driven polarized transport model for phyllotaxis. Proc. Natl. Acad. Sci. U. S. A. 103 (5), 1633-1638. doi: 10.1073/pnas.0509839103

Kameoka, H., Dun, E. A., Lopez-Obando, M., Brewer, P. B., de Saint Germain, A., Rameau, C., et al. (2016). Phloem transport of the receptor DWARF14 protein is required for full function of strigolactones. Plant Physiol. 172 (3), 1844-1852. doi: 10.1104/pp.16.01212

Kebrom, T. H. (2017). A growing stem inhibits bud outgrowth-the overlooked theory of apical dominance. Front. Plant Sci. 8, 1874. doi: 10.3389/fpls.2017.01874

Kebrom, T. H., Brutnell, T. P., and Finlayson, S. A. (2010). Suppression of sorghum axillary bud outgrowth by shade, phyB and defoliation signalling pathways. Plant Cell Environ. 33 (1), 48-58. doi: 10.1111/j.1365-3040.2009.02050.x

Kebrom, T. H., Burson, B. L., and Finlayson, S. A. (2006). Phytochrome B represses teosinte branched 1 expression and induces sorghum axillary bud outgrowth in response to light signals. Plant Physiol. 140 (3), 1109-1117. doi: 10.1104/ pp.105.074856

Kebrom, T. H., Chandler, P. M., Swain, S. M., King, R. W., Richards, R. A., and Spielmeyer, W. (2012). Inhibition of tiller bud outgrowth in the tin mutant of wheat is associated with precocious internode development. Plant Physiol. 160 (1), 308-318. doi: 10.1104/pp.112.197954

Kebrom, T. H., and Mullet, J. E. (2015). Photosynthetic leaf area modulates tiller bud outgrowth in sorghum. Plant Cell Environ. 38 (8), 1471-1478. doi: $10.1111 /$ pce. 12500

Kebrom, T. H., and Mullet, J. E. (2016). Transcriptome profiling of tiller buds provides new insights into PhyB regulation of tillering and indeterminate growth in sorghum. Plant Physiol. 170 (4), 2232-2250. doi: 10.1104/pp.16.00014

Kieffer, M., Fuller, M. P., and Jellings, A. J. (1998). Explaining curd and spear geometry in broccoli, cauliflower and 'romanesco': quantitative variation in activity of primary meristems. Planta 206 (1), 34-43. doi: 10.1007/s004250050371

Kim, H. K., Luquet, D., van Oosterom, E., Dingkuhn, M., and Hammer, G. (2010a). Regulation of tillering in sorghum: genotypic effects. Ann. Bot. 106 (1), 69-78. doi: $10.1093 / \mathrm{aob} / \mathrm{mcq} 080$

Kim, H. K., van Oosterom, E., Dingkuhn, M., Luquet, D., and Hammer, G. (2010b). Regulation of tillering in sorghum: environmental effects. Ann. Bot. 106 (1), 57-67. doi: 10.1093/aob/mcq079

Knox, J. P., and Wareing, P. F. (1984). Apical dominance in Phaseolus vulgaris 1the possible roles of abscisic and indole-3-acetic-acid. J. Exp. Bot. 35 (151), 239-244. doi: $10.1093 / \mathrm{jxb} / 35.2 .239$
Kohlen, W., Charnikhova, T., Liu, Q., Bours, R., Domagalska, M. A., Beguerie, S., et al. (2011). Strigolactones are transported through the xylem and play a key role in shoot architectural response to phosphate deficiency in nonarbuscular mycorrhizal host Arabidopsis. Plant Physiol. 155 (2), 974-987. doi: 10.1104/ pp.110.164640

Kudo, T., Kiba, T., and Sakakibara, H. (2010). Metabolism and long-distance translocation of cytokinins. J. Integr. Plant Biol. 52 (1), 53-60. doi: $10.1111 /$ j.1744-7909.2010.00898.x

Lacointe, A. (2000). Carbon allocation among tree organs: a review of basic processes and representation in functional-structural tree models. Ann. Forest Sci. 57 (5-6), 521-533. doi: 10.1051/forest:2000139

Lacombe, B., and Achard, P. (2016). Long-distance transport of phytohormones through the plant vascular system. Curr. Opin. Plant Biol. 34, 1-8. doi: 10.1016/j.pbi.2016.06.007

Lafarge, T., Seassau, C., Martin, M., Bueno, C., Clement-Vidal, A., Schreck, E., et al. (2010). Regulation and recovery of sink strength in rice plants grown under changes in light intensity. Funct. Plant Biol. 37 (5), 413-428. doi: 10.1071/FP09137

Lang, G. A., Early, J. D., Martin, G. C., and Darnell, R. L. (1987). Endodormancy, paradormancy, and ecodormancy-physiological terminology and classification for dormancy research. Hortscience 22 (3), 371-377.

Lastdrager, J., Hanson, J., and Smeekens, S. (2014). Sugar signals and the control of plant growth and development. J. Exp. Bot. 65 (3), 799-807. doi: 10.1093/ jxb/ert474

Lau, O. S., and Deng, X. W. (2012). The photomorphogenic repressors COP1 and DET1: 20 years later. Trends Plant Sci. 17 (10), 584-593. doi: 10.1016/j. tplants.2012.05.004

Lazar, G., and Goodman, H. M. (2006). MAX1, a regulator of the flavonoid pathway, controls vegetative axillary bud outgrowth in Arabidopsis. Proc. Natl. Acad. Sci. U. S. A. 103 (2), 472-476. doi: 10.1073/pnas.0509463102

Le Moigne, M.-A., Guérin, V., Furet, P. M., Billard, V., Lebrec, A., Spichal, L., et al. (2018). Asparagine and sugars are both required to sustain secondary axis elongation after bud outgrowth in Rosa hybrida. J. Plant Physiol. 222, 17-27. doi: 10.1016/j.jplph.2017.12.013

Leduc, N., Roman, H., Barbier, F., Péron, T., Huché-Thélier, L., Lothier, J., et al. (2014). Light signaling in bud outgrowth and branching in plants. Plants 3, 223-250. doi: 10.3390/plants3020223

Lee, H. J., Park, Y. J., Ha, J. H., Baldwin, I. T., and Park, C. M. (2017). Multiple routes of light signaling during root photomorphogenesis. Trends Plant Sci. 22 (9), 803-812. doi: 10.1016/j.tplants.2017.06.009

Lejay, L., Gansel, X., Cerezo, M., Tillard, P., Muller, C., Krapp, A., et al. (2003). Regulation of root ion transporters by photosynthesis: functional importance and relation with hexokinase. Plant Cell 15 (9), 2218-2232. doi: 10.1105/ tpc. 013516

Lejay, L., Wirth, J., Pervent, M., Cross, J. M. F., Tillard, P., and Gojon, A. (2008). Oxidative pentose phosphate pathway-dependent sugar sensing as a mechanism for regulation of root ion transporters by photosynthesis. Plant Physiol. 146 (4), 2036-2053. doi: 10.1104/pp.107.114710

Letort, V., Cournede, P. H., Mathieu, A., de Reffye, P., and Constant, T. (2008). Parametric identification of a functional-structural tree growth model and application to beech trees (Fagus sylvatica). Funct. Plant Biol. 35 (9-10), 951963. doi: 10.1071/FP08065

Li-Marchetti, C., Le Bras, C., Relion, D., Citerne, S., Huche-Thelier, L., Sakr, S., et al. (2015). Genotypic differences in architectural and physiological responses to water restriction in rose bush. Front. Plant Sci. 6, 355. doi: 10.3389/fpls.2015.00355

Li, C. J., and Bangerth, F. (1999). Autoinhibition of indoleacetic acid transport in the shoots of two-branched pea (Pisum sativum) plants and its relationship to correlative dominance. Physiol. Plant. 106 (4), 415-420. doi: 10.1034/j.1399-3054.1999.106409.x

Li, L., and Sheen, J. (2016). Dynamic and diverse sugar signaling. Curr. Opin. Plant Biol. 33, 116-125. doi: 10.1016/j.pbi.2016.06.018

Li, M. J., Wei, Q. P., Xiao, Y. S., and Peng, F. T. (2018). The effect of auxin and strigolactone on ATP/ADP isopentenyltransferase expression and the regulation of apical dominance in peach. Plant Cell Reports 37 (12), 1693-1705. doi: 10.1007/s00299-018-2343-0

Li, X. J., Cai, W. G., Liu, Y. L., Li, H., Fu, L. W., Liu, Z. Y., et al. (2017). Differential TOR activation and cell proliferation in Arabidopsis root and shoot apexes. Proc. Natl. Acad. Sci. U. S. A. 114 (10), 2765-2770. doi: 10.1073/pnas.1618782114 
Ligerot, Y., de Saint Germain, A., Waldie, T., Troadec, C., Citerne, S., Kadakia, N., et al. (2017). The pea branching RMS2 gene encodes the PsAFB4/5 auxin receptor and is involved in an auxin-strigolactone regulation loop. PloS Genet. 13 (12), e1007089. doi: 10.1371/journal.pgen.1007089

Lin, H., Wang, R. X., Qian, Q., Yan, M. X., Meng, X. B., Fu, Z. M., et al. (2009). DWARF27, an iron-containing protein required for the biosynthesis of strigolactones, regulates rice tiller bud outgrowth. Plant Cell 21 (5), 1512-1525. doi: 10.1105/tpc.109.065987

Liu, Y., Wang, Q. S., Ding, Y. F., Li, G. H., Xu, J. X., and Wang, S. H. (2011). Effects of external ABA, GA(3) and NAA on the tiller bud outgrowth of rice is related to changes in endogenous hormones. Plant Growth Regul. 65 (2), 247-254. doi: 10.1007/s10725-011-9594-x

Ljung, K., Bhalerao, R. P., and Sandberg, G. (2001). Sites and homeostatic control of auxin biosynthesis in Arabidopsis during vegetative growth. Plant J. 28 (4), 465-474. doi: 10.1046/j.1365-313X.2001.01173.x

Lo, S. F., Yang, S. Y., Chen, K. T., Hsing, Y. L., Zeevaart, J. A. D., Chen, L. J., et al. (2008). A novel class of gibberellin 2-oxidases control semidwarfism, tillering, and root development in rice. Plant Cell 20 (10), 2603-2618. doi: 10.1105/ tpc.108.060913

Luquet, D., Dingkuhn, M., Kim, H., Tambour, L., and Clement-Vidal, A. (2006). EcoMeristem, a model of morphogenesis and competition among sinks in rice. 1. Concept, validation and sensitivity analysis. Funct. Plant Biol. 33 (4), 309-323. doi: 10.1071/FP05266

Mader, J. C., Emery, R. J. N., and Turnbull, C. G. N. (2003). Spatial and temporal changes in multiple hormone groups during lateral bud release shortly following apex decapitation of chickpea (Cicer arietinum) seedlings. Physiol. Plant. 119 (2), 295-308. doi: 10.1034/j.1399-3054.2003.00179.x

Martin-Fontecha, E. S., Tarancon, C., and Cubas, P. (2018). To grow or not to grow, a power-saving program induced in dormant buds. Curr. Opin. Plant Biol. 41, 102-109. doi: 10.1016/j.pbi.2017.10.001

Martinez-Bello, L., Moritz, T., and Lopez-Diaz, I. (2015). Silencing C-19-GA 2-oxidases induces parthenocarpic development and inhibits lateral branching in tomato plants. J. Exp. Bot. 66 (19), 5897-5910. doi: 10.1093/jxb/erv300

Mason, M. G., Ross, J. J., Babst, B. A., Wienclaw, B. N., and Beveridge, C. A. (2014). Sugar demand, not auxin, is the initial regulator of apical dominance. Proc. Natl. Acad. Sci. U. S. A. 111 (16), 6092-6097. doi: 10.1073/pnas.1322045111

Mathieu, A., Cournede, P. H., Letort, V., Barthelemy, D., and de Reffye, P. (2009). A dynamic model of plant growth with interactions between development and functional mechanisms to study plant structural plasticity related to trophic competition. Ann. Bot. 103 (8), 1173-1186. doi: 10.1093/aob/mcp054

Mauriat, M., Sandberg, L. G., and Moritz, T. (2011). Proper gibberellin localization in vascular tissue is required to control auxin-dependent leaf development and bud outgrowth in hybrid aspen. Plant J. 67 (5), 805-816. doi: 10.1111/j.1365-313X.2011.04635.x

Mawphlang, O. I. L., and Kharshiing, E. V. (2017). Photoreceptor mediated plant growth responses: implications for photoreceptor engineering toward improved performance in crops. Front. Plant Sci. 8, 1181. doi: 10.3389/fpls.2017.01181

Minakuchi, K., Kameoka, H., Yasuno, N., Umehara, M., Luo, L., Kobayashi, K., et al. (2010). FINE CULM1 (FC1) works downstream of strigolactones to inhibit the outgrowth of axillary buds in rice. Plant Cell Physiol. 51 (7), 11271135. doi: $10.1093 / \mathrm{pcp} / \mathrm{pcq} 083$

Mitchell, K. J. (1953). Influence of light and temperature on the growth of ryegrass (Lolium spp.). II. The control of lateral bud development. Physiol. Plant. 6 (3), 425-443. doi: 10.1111/j.1399-3054.1953.tb08401.x

Moore, B., Zhou, L., Rolland, F., Hall, Q., Cheng, W. H., Liu, Y. X., et al. (2003). Role of the Arabidopsis glucose sensor HXK1 in nutrient, light, and hormonal signaling. Science 300 (5617), 332-336. doi: 10.1126/science.1080585

Morris, D. A. (1977). Transport of exogenous auxin in 2-branched dwarf peaseedlings (Pisum sativum L.) - some implications for polarity and apical dominance. Planta 136 (1), 91-96. doi: 10.1007/BF00387930

Mostofa, M. G., Li, W. Q., Nguyen, K. H., Fujita, M., and Tran, L. S. P. (2018). Strigolactones in plant adaptation to abiotic stresses: an emerging avenue of plant research. Plant Cell Environ. 41 (10), 2227-2243. doi: 10.1111/pce.13364

Mueller, D., and Leyser, O. (2011). Auxin, cytokinin and the control of shoot branching. Ann. Bot. 107 (7), 1203-1212. doi: 10.1093/aob/mcr069

Muller, D., Waldie, T., Miyawaki, K., To, J. P. C., Melnyk, C. W., Kieber, J. J., et al. (2015). Cytokinin is required for escape but not release from auxin mediated apical dominance. Plant J. 82 (5), 874-886. doi: 10.1111/tpj.12862
Nagel, K. A., Schurr, U., and Walter, A. (2006). Dynamics of root growth stimulation in Nicotiana tabacum in increasing light intensity. Plant Cell Environ. 29 (10), 1936-1945. doi: 10.1111/j.1365-3040.2006.01569.x

Ni, J., Zhao, M. L., Chen, M. S., Pan, B. Z., Tao, Y. B., and Xu, Z. F. (2017). Comparative transcriptome analysis of axillary buds in response to the shoot branching regulators gibberellin A3 and 6-benzyladenine in Jatropha curcas. Sci. Rep. 7, 11417. doi: 10.1038/s41598-017-11588-0

Nordstrom, A., Tarkowski, P., Tarkowska, D., Norbaek, R., Astot, C., Dolezal, K., et al. (2004). Auxin regulation of cytokinin biosynthesis in Arabidopsis thaliana: a factor of potential importance for auxin-cytokinin-regulated development. Proc. Natl. Acad. Sci. U. S. A. 101 (21), 8039-8044. doi: 10.1073/ pnas.0402504101

Ohashi, M., Ishiyama, K., Kojima, S., Kojima, M., Sakakibara, H., Yamaya, T., et al. (2017). Lack of Cytosolic glutamine synthetase 1;2 activity reduces nitrogendependent biosynthesis of cytokinin required for axillary bud outgrowth in rice seedlings. Plant Cell Physiol. 58 (4), 679-690. doi: 10.1093/pcp/pcx022

Ohashi, M., Ishiyama, K., Kojima, S., Konishi, N., Sasaki, K., Miyao, M., et al. (2018). Outgrowth of rice tillers requires availability of glutamine in the basal portions of shoots. Rice 11, 31. doi: 10.1186/s12284-018-0225-2

Olszewski, N., Sun, T. P., and Gubler, F. (2002). Gibberellin signaling: biosynthesis, catabolism, and response pathways. Plant Cell 14, S61-S80. doi: 10.1105/ tpc. 010476

Ongaro, V., and Leyser, O. (2008). Hormonal control of shoot branching. J. Exp. Bot. 59 (1), 67-74. doi: 10.1093/jxb/erm134

Otori, K., Tamoi, M., Tanabe, N., and Shigeoka, S. (2017). Enhancements in sucrose biosynthesis capacity affect shoot branching in Arabidopsis. Biosci. Biotechnol. Biochem. 81 (8), 1470-1477. doi: 10.1080/09168451.2017.1321954

Palubicki, W., Horel, K., Longay, S., Runions, A., Lane, B., Mech, R., et al. (2009). Self-organizing tree models for image synthesis. ACM Trans. Graphics 28 (3), 58. doi: 10.1145/1531326.1531364

Perttunen, J., Sievanen, R., and Nikinmaa, E. (1998). LIGNUM: a model combining the structure and the functioning of trees. Ecol. Model. 108 (1-3), 189-198. doi: 10.1016/S0304-3800(98)00028-3

Perttunen, J., Sievanen, R., Nikinmaa, E., Salminen, H., Saarenmaa, H., and Vakeva, J. (1996). LIGNUM: A tree model based on simple structural units. Ann. Bot. 77 (1), 87-98. doi: 10.1006/anbo.1996.0011

Pfeiffer, A., Janocha, D., Dong, Y. H., Medzihradszky, A., Schone, S., Daum, G., et al. (2016). Integration of light and metabolic signals for stem cell activation at the shoot apical meristem. ELife 5, e17023. doi: 10.7554/eLife.17023

Pierik, R., and Testerink, C. (2014). The art of being flexible: how to escape from shade, salt, and drought. Plant Physiol. 166 (1), 5-22. doi: 10.1104/ pp.114.239160

Prasad, T. K., Li, X., Abdelrahman, A. M., Hosokawa, Z., Cloud, N. P., Lamotte, C. E., et al. (1993). Does auxin play a role in the release of apical dominance by shoot inversion in ipomoea nil. Ann. Bot. 71 (3), 223-229. doi: 10.1006/anbo.1993.1028

Prusinkiewicz, P., Crawford, S., Smith, R. S., Ljung, K., Bennett, T., Ongaro, V., et al. (2009). Control of bud activation by an auxin transport switch. Proc. Natl. Acad. Sci. U. S. A. 106 (41), 17431-17436. doi: 10.1073/pnas.0906696106

Prusinkiewicz, P., Erasmus, Y., Lane, B., Harder, L. D., and Coen, E. (2007). Evolution and development of inflorescence architectures. Science 316 (5830), 1452-1456. doi: 10.1126/science.1140429

Quail, P. H. (2002). Phytochrome photosensory signalling networks. Nat. Rev. Mol. Cell Biol. 3 (2), 85-93. doi: 10.1038/nrm728

Rabot, A., Henry, C., Ben Baaziz, K., Mortreau, E., Azri, W., Lothier, J., et al. (2012). Insight into the role of sugars in bud burst under light in the rose. Plant Cell Physiol. 53 (6), 1068-1082. doi: 10.1093/pcp/pcs051

Rabot, A., Portemer, V., Peron, T., Mortreau, E., Leduc, N., Hamama, L., et al. (2014). Interplay of sugar, light and gibberellins in expression of rosa hybrida vacuolar invertase 1 regulation. Plant Cell Physiol. 55 (10), 1734-1748. doi: $10.1093 / \mathrm{pcp} / \mathrm{pcu} 106$

Ragni, L., Nieminen, K., Pacheco-Villalobos, D., Sibout, R., Schwechheimer, C., and Hardtke, C. S. (2011). Mobile gibberellin directly stimulates arabidopsis hypocotyl xylem expansion. Plant Cell 23 (4), 1322-1336. doi: 10.1105/ tpc. 111.084020

Rameau, C., Bertheloot, J., Leduc, N., Andrieu, B., Foucher, F., and Sakr, S. (2015). Multiple pathways regulate shoot branching. Front. Plant Sci. 5 , 741. doi: 10.3389/fpls.2014.00741 
Reddy, S. K., and Finlayson, S. A. (2014). Phytochrome B promotes branching in Arabidopsis by suppressing auxin signaling. Plant Physiol. 164 (3), 1542-1550. doi: $10.1104 /$ pp.113.234021

Reddy, S. K., Holalu, S. V., Casal, J. J., and Finlayson, S. A. (2013). Abscisic acid regulates axillary bud outgrowth responses to the ratio of red to far-red light. Plant Physiol. 163 (2), 1047-1058. doi: 10.1104/pp.113.221895

Refahi, Y., Brunoud, G., Farcot, E., Jean-Marie, A., Pulkkinen, M., Vernoux, T., et al. (2016). A stochastic multicellular model identifies biological watermarks from disorders in self-organized patterns of phyllotaxis. ELife 5, e14093. doi: 10.7554/eLife.14093

Rinne, P., Tuominen, H., and Sundberg, B. (1993). Growth-patterns and endogenous indole-3-acetic-acid concentrations in current-year coppice shoots and seedlings of 2 betula species. Physiol. Plant. 88 (3), 403-412. doi: 10.1111/j.1399-3054.1993.tb01352.x

Rohde, A., Van Montagu, M., and Boerjan, W. (1999). The abscisic acid-insensitive 3 (ABI3) gene is expressed during vegetative quiescence processes in Arabidopsis. Plant Cell Environ. 22 (3), 261-270. doi: 10.1046/j.1365-3040.1999.00428.x

Roitsch, T., and Ehness, R. (2000). Regulation of source/sink relations by cytokinins. Plant Growth Regul. 32 (2-3), 359-367. doi: 10.1023/A:1010781500705

Rolland, F., Baena-Gonzalez, E., and Sheen, J. (2006). Annual Review of Plant Biology in Sugar sensing and signaling in plants: conserved and novel mechanisms. Annu. Rev. Plant Biol. 675-709. doi: 10.1146/annurev. arplant.57.032905.105441

Roman, H., Girault, T., Barbier, F., Peron, T., Brouard, N., Pencik, A., et al. (2016). Cytokinins are initial targets of light in the control of bud outgrowth(1 open). Plant Physiol. 172 (1), 489-509. doi: 10.1104/pp.16.00530

Romano, C. P., Hein, M. B., and Klee, H. J. (1991). Inactivation of auxin in tobacco transformed with the indoleacetic-acid lysine synthetase gene of pseudomonassavastanoi. Genes Dev. 5 (3), 438-446. doi: 10.1101/gad.5.3.438

Runions, A., Lane, B., and Prusinkiewicz, P. (2007). "Modeling trees with a spacecolonization algorithm," in Proceedings of the 2007 Eurographics Workshop on Natural Phenomena, eds D. Ebert and S. Merillou (Geneva: The Eurographics Association), 63-70.

Sachs, T. (1981). The control of the patterned differentiation of vascular tissues. Adv. Bot. Res. Incorp. Adv. Plant Pathol. 9, 151-262. doi: 10.1016/ S0065-2296(08)60351-1

Sachs, T., and Thimann, K. V. (1967). The role of auxins and cytokinins in the release of buds from dominance. Am. J. Bot. 54 (1), 136-144. doi: 10.1002/ j.1537-2197.1967.tb06901.x

Sakr, S., Wang, M., Dedaldechamp, F., Perez-Garcia, M. D., Oge, L., Hamama, L., et al. (2018). The sugar-signaling hub: overview of regulators and interaction with the hormonal and metabolic network. Int. J. Mol. Sci. 19 (9), 2506. doi: 10.3390/ijms19092506

Sakuraba, Y., and Yanagisawa, S. (2018). Light signalling-induced regulation of nutrient acquisition and utilisation in plants. Semin. Cell Dev. Biol. 83, 123-132. doi: 10.1016/j.semcdb.2017.12.014

Sauer, M., Balla, J., Luschnig, C., Wisniewska, J., Reinohl, V., Friml, J., et al. (2006). Canalization of auxin flow by Aux/IAA-ARF-dependent feedback regulation of PIN polarity. Genes Dev. 20 (20), 2902-2911. doi: 10.1101/gad.390806

Shen, H., Luong, P., and Huq, E. (2007). The F-Box protein MAX2 functions as a positive regulator of photomorphogenesis in Arabidopsis (1 C W OA ). Plant Physiol. 145 (4), 1471-1483. doi: 10.1104/pp.107.107227

Shen, H., Zhu, L., Bu, Q. Y., and Huq, E. (2012). MAX2 affects multiple hormones to promote photomorphogenesis. Mol. Plant 5 (3), 750-762. doi: 10.1093/mp/sss029

Sherson, S. M., Alford, H. L., Forbes, S. M., Wallace, G., and Smith, S. M. (2003). Roles of cell-wall invertases and monosaccharide transporters in the growth and development of Arabidopsis. J. Exp. Bot. 54 (382), 525-531. doi: 10.1093/ jxb/erg055

Shimizu-Sato, S., Tanaka, M., and Mori, H. (2009). Auxin-cytokinin interactions in the control of shoot branching. Plant Mol. Biol. 69 (4), 429-435. doi: 10.1007/ s11103-008-9416-3

Shinohara, N., Taylor, C., and Leyser, O. (2013). Strigolactone can promote or inhibit shoot branching by triggering rapid depletion of the auxin efflux protein PIN1 from the plasma membrane. PloS Biol. 11 (1), e1001474. doi: 10.1371/ journal.pbio.1001474

Signorelli, S., Agudelo-Romero, P., Meitha, K., Foyer, C. H., and Considine, M. J. (2018). Roles for light, energy, and oxygen in the fate of quiescent axillary buds. Plant Physiol. 176 (2), 1171-1181. doi: 10.1104/pp.17.01479
Silverstone, A. L., Mak, P. Y. A., Martinez, E. C., and Sun, T. P. (1997). The new RGA locus encodes a negative regulator of gibberellin response in Arabidopsis thaliana. Genetics 146 (3), 1087-1099.

Simon, N. M. L., Sawkins, E., and Dodd, A. N. (2018). Involvement of the SnRK1 subunit KIN10 in sucrose-induced hypocotyl elongation. Plant Signaling Behav. 13 (6), e1457913. doi: 10.1080/15592324.2018.1457913

Smith, R. S., Guyomarc'h, S., Mandel, T., Reinhardt, D., Kuhlemeier, C., and Prusinkiewicz, P. (2006). A plausible model of phyllotaxis. Proc. Natl. Acad. Sci. U. S. A. 103 (5), 1301-1306. doi: 10.1073/pnas.0510457103

Snowden, K. C., Simkin, A. J., Janssen, B. J., Templeton, K. R., Loucas, H. M., Simons, J. L., et al. (2005). The decreased apical dominance 1/petunia hybrida carotenoid cleavage dioxygenase 8 gene affects branch production and plays a role in leaf senescence, root growth, and flower development. Plant Cell 17 (3), 746-759. doi: 10.1105/tpc.104.027714

Su, H. W., Abernathy, S. D., White, R. H., and Finlayson, S. A. (2011). Photosynthetic photon flux density and phytochrome B interact to regulate branching in Arabidopsis. Plant Cell Environ. 34 (11), 1986-1998. doi: 10.1111/j.1365-3040.2011.02393.x

Takei, K., Takahashi, T., Sugiyama, T., Yamaya, T., and Sakakibara, H. (2002). Multiple routes communicating nitrogen availability from roots to shoots: a signal transduction pathway mediated by cytokinin. J. Exp. Bot. 53 (370), 971977. doi: 10.1093/jexbot/53.370.971

Tan, M., Li, G. F., Liu, X. J., Cheng, F., Ma, J. J., Zhao, C. P., et al. (2018). Exogenous application of $\mathrm{GA}(3)$ inactively regulates axillary bud outgrowth by influencing of branching-inhibitors and bud-regulating hormones in apple (Malus domestica Borkh.). Mol. Genet. Genomics 293 (6), 1547-1563. doi: 10.1007/s00438-018-1481-y

Tanaka, M., Takei, K., Kojima, M., Sakakibara, H., and Mori, H. (2006). Auxin controls local cytokinin biosynthesis in the nodal stem in apical dominance. Plant J. 45 (6), 1028-1036. doi: 10.1111/j.1365-313X.2006.02656.x

Tarancon, C., Gonzalez-Grando, E., Oliveros, J. C., Nicolas, M., and Cubas, P. (2017). A conserved carbon starvation response underlies bud dormancy in woody and herbaceous species. Front. Plant Sci. 8 (788). doi: 10.3389/fpls.2017.00788

Teichmann, T., and Muhr, M. (2015). Shaping plant architecture. Front. Plant Sci. 6, 233. doi: 10.3389/fpls.2015.00233

Thimann, K. V., and Skoog, F. (1933). Studies on the growth hormone of plants. III. The inhibitory action of the growth substance on bud development. Proc. Natl. Acad. Sci. U. S. A. 19, 714-716. doi: 10.1073/pnas.19.7.714

Thimann, K. V., and Skoog, F. (1934). On the inhibition of bud development and other functions of growth substance in Vicia Faba. Proc. R. Soc. Lond. B. 114, 317-339. doi: 10.1098/rspb.1934.0010

Tsai, A. Y. L., and Gazzarrini, S. (2014). Trehalose-6-phosphate and SnRK1 kinases in plant development and signaling: the emerging picture. Front. Plant Sci. 5, 119. doi: 10.3389/fpls.2014.00119

Tucker, D. J., and Mansfield, T. A. (1972). Effects of light quality on apical dominance in xanthium-strumarium and associated changes in endogenous levels of abscisic acid and cytokinins. Planta 102 (2), 140-14+. doi: 10.1007/BF00384868

Turnbull, C. G. N., Raymond, M. A. A., Dodd, I. C., and Morris, S. E. (1997). Rapid increases in cytokinin concentration in lateral buds of chickpea (Cicer arietinum L) during release of apical dominance. Planta 202 (3), 271-276. doi: 10.1007/s004250050128

Umehara, M., Hanada, A., Yoshida, S., Akiyama, K., Arite, T., Takeda-Kamiya, N., et al. (2008). Inhibition of shoot branching by new terpenoid plant hormones. Nature 455 (7210), 195-U129. doi: 10.1038/nature07272

Urriola, J., and Rathore, K. S. (2015). Overexpression of a glutamine synthetase gene affects growth and development in sorghum. Transgenic Res. 24 (3), 397 407. doi: 10.1007/s11248-014-9852-6

Vishwakarma, K., Upadhyay, N., Kumar, N., Yadav, G., Singh, J., Mishra, R. K., et al. (2017). Abscisic acid signaling and abiotic stress tolerance in plants: a review on current knowledge and future prospects. Front. Plant Sci. 8, 161. doi: $10.3389 /$ fpls. 2017.00161

Waldie, T., and Leyser, O. (2018). Cytokinin targets auxin transport to promote shoot branching. Plant Physiol. 177 (2), 803-818. doi: 10.1104/pp.17.01691

Wang, D. L., Gao, Z. Z., Du, P. Y., Xiao, W., Tan, Q. P., Chen, X. D., et al. (2016a). Expression of ABA metabolism-related genes suggests similarities and differences between seed dormancy and bud dormancy of peach (Prunus persica). Front. Plant Sci. 6, 1248. doi: 10.3389/fpls.2015.01248

Wang, H. W., Chen, W. X., Eggert, K., Charnikhova, T., Bouwmeester, H., Schweizer, P., et al. (2018). Abscisic acid influences tillering by modulation of strigolactones in barley. J. Exp. Bot. 69 (16), 3883-3898. doi: 10.1093/jxb/ery200 
Wang, M., Le Moigne, M. A., Bertheloot, J., Crespel, L., Perez-Garcia, M. D., Oge, L., et al. (2019). BRANCHED1: a key hub of shoot branching. Front. Plant Sci. 10, 76. doi: 10.3389/fpls.2019.00076

Wang, W., Hao, Q., Tian, F., Li, Q., and Wang, W. (2016b). Cytokinin-regulated sucrose metabolism in stay-green wheat phenotype. PloS One 11 (8), e0161351. doi: 10.1371/journal.pone.0161351

Warren-Wilson, J. (1972). "Crop processes in Controlled Environments.," in Control of crop processes (London: Academic Press), 7-30.

Wenden, B., Dun, E. A., Hanan, J., Andrieu, B., Weller, J. L., Beveridge, C. A., et al. (2009). Computational analysis of flowering in pea (Pisum sativum). New Phytol. 184 (1), 153-167. doi: 10.1111/j.1469-8137.2009.02952.x

White, J. C., and Mansfield, T. A. (1977). Correlative inhibition of lateral bud growth in Pisum sativum 1 and Phaseolus vulgaris 1 -studies of role of abscisic acid. Ann. Bot. 41 (176), 1163-1170. doi: 10.1093/oxfordjournals. aob.a085406

Wickson, M., and Thimann, K. (1958). The antagonism of auxin and kinetin in apical dominance. Physiol. Plant. 11, 62-74. doi: 10.1111/j.1399-3054.1958. tb08426.x

Wingler, A. (2018). Transitioning to the next phase: the role of sugar signaling throughout the plant life cycle. Plant Physiol. 176 (2), 1075-1084. doi: 10.1104/ pp.17.01229

Wisniewska, J., Xu, J., Seifertova, D., Brewer, P. B., Ruzicka, K., Blilou, I., et al. (2006). Polar PIN localization directs auxin flow in plants. Science 312 (5775), 883-883. doi: 10.1126/science.1121356

Xi, L., Wen, C., Fang, S., Chen, X. L., Nie, J., Chu, J. F., et al. (2015). Impacts of strigolactone on shoot branching under phosphate starvation in chrysanthemum (Dendranthema grandiflorum cv. Jinba). Front. Plant Sci. 6 (694). doi: 10.3389/ fpls.2015.00694

Xu, J. X., Zha, M. R., Li, Y., Ding, Y. F., Chen, L., Ding, C. Q., et al. (2015). The interaction between nitrogen availability and auxin, cytokinin, and strigolactone in the control of shoot branching in rice (Oryza sativa L.). Plant Cell Reports 34 (9), 1647-1662. doi: 10.1007/s00299-015-1815-8

Yamaguchi, S. (2008). Gibberellin metabolism and its regulation. Annu. Rev. Plant Biol. 59, 225-251. doi: 10.1146/annurev.arplant.59.032607.092804

Yao, C., and Finlayson, S. A. (2015). Abscisic acid is a general negative regulator of arabidopsis axillary bud growth. Plant Physiol. 169 (1), 611-626. doi: 10.1104/ pp.15.00682
Yoshida, S., Mandel, T., and Kuhlemeier, C. (2011). Stem cell activation by light guides plant organogenesis. Genes Dev. 25 (13), 1439-1450. doi: 10.1101/ gad.631211

Young, N. F., Ferguson, B. J., Antoniadi, I., Bennett, M. H., Beveridge, C. A., and Turnbull, C. G. N. (2014). Conditional auxin response and differential cytokinin profiles in shoot branching mutants. Plant Physiol. 165 (4), 1723 1736. doi: 10.1104/pp.114.239996

Yuan, C. Q., Ahmad, S., Cheng, T. R., Wang, J., Pan, H. T., Zhao, L. J., et al. (2018). Red to far-red light ratio modulates hormonal and genetic control of axillary bud outgrowth in chrysanthemum (Dendranthema grandiflorum "Jinba'). Int. J. Mol. Sci. 19 (6), 1590. doi: 10.3390/ijms19061590

Zdarska, M., Dobisova, T., Gelova, Z., Pernisova, M., Dabravolski, S., and Hejatko, J. (2015). Illuminating light, cytokinin, and ethylene signalling crosstalk in plant development. J. Exp. Bot. 66 (16), 4913-4931. doi: 10.1093/ jxb/erv261

Zimmermann, M. H. (1978). Hydraulic architecture of some diffuse-porous trees. Can. J. Bot. 56, 2286-2295. doi: 10.1139/b78-274

Zou, J. H., Zhang, S. Y., Zhang, W. P., Li, G., Chen, Z. X., Zhai, W. X., et al. (2006). The rice HIGH-TILLERING DWARF1 encoding an ortholog of Arabidopsis MAX3 is required for negative regulation of the outgrowth of axillary buds. Plant J. 48 (5), 687-696. doi: 10.1111/j.1365-313X.2006.02916.x

Zubo, Y. O., Yamburenko, M. V., Selivankina, S. Y., Shakirova, F. M., Avalbaev, A. M., Kudryakova, N. V., et al. (2008). Cytokinin stimulates chloroplast transcription in detached barley leaves. Plant Physiol. 148 (2), 1082-1093. doi: $10.1104 /$ pp.108.122275

Conflict of Interest: The authors declare that the research was conducted in the absence of any personal, professional, or financial relationships that could potentially be construed as a conflict of interest.

Copyright (C) 2019 Schneider, Godin, Boudon, Demotes-Mainard, Sakr and Bertheloot. This is an open-access article distributed under the terms of the Creative Commons Attribution License (CC BY). The use, distribution or reproduction in other forums is permitted, provided the original author(s) and the copyright owner(s) are credited and that the original publication in this journal is cited, in accordance with accepted academic practice. No use, distribution or reproduction is permitted which does not comply with these terms. 